\title{
Dynamic simulation of sorption enhanced reaction processes for biodiesel production
}

\author{
Ankur Kapil, Shrikant A Bhat, Jhuma Sadhukhan* \\ Centre for Process Integration,
}

School of Chemical Engineering and Analytical Science

The University of Manchester, Manchester, M60 1QD, UK

\begin{abstract}
*Author to whom correspondence should be addressed
E-mail: jhuma.sadhukhan@manchester.ac.uk
\end{abstract}

Phone : 44-161-3064396 


\begin{abstract}
The objective of this work was to establish fixed bed sorption enhanced reactors (SER) and simulated moving bed reactors (SMBR) for the production of high purity biodiesel (fatty acid methyl ester, FAME) using esterification reactions between fatty acids (FA) in used oils and methanol. This study has demonstrated that these processes have tremendous potential in terms of overcoming the low conversion and separation difficulties that are faced in conventional biodiesel production processes. Additionally, the SMBR process operating conditions can be optimised to produce FAME at a desired purity in a continuous mode. Novelty of this work lays in the development of generic and comprehensive dynamic simulation and systematic parametric analysis frameworks. These were used to deduce the following operating conditions for achieving more than 90\% conversion of FA and $80 \%$ purity of FAME, from a SMBR process: switching time of $900 \mathrm{~s}$, length of $0.25 \mathrm{~m}$ and feed, raffinate and eluent flow rate ratios of $0.41,0.49$ and 0.75 , for a given velocity of $2.4 \times 10^{-4} \mathrm{~m} / \mathrm{s}$ in the reaction zone.
\end{abstract}

Keywords: dynamic simulation, SMBR, sorption enhanced reactor, biodiesel process intensification, esterification kinetics 


\section{Introduction}

\subsection{Process intensification in Biodiesel production}

Process intensification describes a strategy for reduction of physical size, energy requirement and waste production of a chemical process or plant to achieve a given production objective ${ }^{1}$. Biodiesel $(F A M E)$ is a renewable and environmentally friendly fuel produced from renewable resources such as used vegetable oils, refined oils and animal fats which are mainly triglycerides and free fatty acids (FFA $)^{2}$. Biodiesel production is associated with mass transfer limited reactions due to the immiscible nature of the reactants, i.e., $F A$ and alcohol etc ${ }^{3}$. Hence, studies have focused on the application of process intensification to improve the mass transfer, conversion and product purity, minimisation of wastes and usage of utility / energy and downsizing of equipment in biodiesel systems. Sun et al. ${ }^{3}$ reviewed the process intensification methods and reactors for the production of biodiesel. They discussed the application of membrane reactor, micro-reactor, etc. and technologies such as microwave, ultrasound, etc. to enhance heat exchange and mass transports in the biodiesel production.

Harvey et al. ${ }^{4}$ demonstrated economic production of biodiesel at pilot scale oscillatory flow reactor. The oscillatory flow reactors are units with equally spaced orifice plate baffles tubes, where high heat and mass transfer is obtained by superimposing oscillatory motion over plug flow in between orifices plates ${ }^{4}$. The oscillatory flow mechanism reduces the minimum Reynolds number requirement for maintaining a good mixing and lowers the length to diameter ratio and thereby the capital cost of the reactor ${ }^{4}$. The microreactors also provide a high surface-area-to-volume ratio and heat and mass transfer 
coefficients compared to the conventional chemical reactors for biodiesel production ${ }^{5}$. Wen et al. ${ }^{6}$ showed that the residence time required for microreactors was significantly lesser compared to traditional CSTR, to achieve the same conversion. Additionally, microreactors consumed less energy than CSTR during biodiesel synthesis ${ }^{6}$.

Research efforts have also been on the combined reaction separation processes. The reaction to convert $F A$ to $F A M E$ (biodiesel) is an equilibrium driven process $^{7}$. Furthermore, equilibrium in biodiesel reactions can be shifted by combining reaction and separation in the same unit ${ }^{8,9}$. This avoids the use of excess reactants. Such combined reactors include membrane reactors, reactive distillation, and reactive adsorption etc. The membrane reactors have been demonstrated to enhance the rate of reaction by removing the products from the reaction mixture and maintaining a reasonable heat and mass transfer between the immiscible phases for biodiesel production ${ }^{10-15}$. Reactive distillation is one of the strategies that has been used to combine esterification reaction between $F A$ and methanol and separation by removal of the by-product water, in a single unit ${ }^{8,9,16-18}$. The reactive adsorption (also known as sorption enhanced reaction (SER) or chromatographic reactors) is another path for high conversion by shifting the equilibrium towards the right by preferential adsorption of one of the products. This work focuses on the dynamic modelling of such processes and further extends to simulated moving bed reactor $(\mathrm{SMBR})$ process design and decision making. The processes are aimed at a continuous production of pure biodiesel by a combination of adsorption and reaction in same units. 


\subsection{Applications of SMBR processes in biodiesel production}

The working of a SER for the generation of FAME can be briefly described as follows. The feed to the chromatographic reactor is a mixture of methanol $\left(\mathrm{CH}_{3} \mathrm{OH}\right)$ and $\mathrm{FA}$. The reactants in the feed are adsorbed by resin, which acts as a catalyst as well as an adsorbent. The reactions take place in the adsorbed phase. Methanol used in excess acts as a carrier of the reactant $F A$ and products, FAME and water through the adsorbed phase. Water is more strongly adsorbed by the resin in comparison to FAME and FA. Thus, high purity FAME is recovered through raffinate, while water is eluted with methanol in the extract phase. Higher conversion is obtained from this system due to the separation of the product water.

Chromatographic reactors in the form of batch processes are commonly used. However, the batch chromatographic reactor is not the most efficient process as it doesn't lead to complete separation of the reactants from the prodcuts ${ }^{19}$. To increase the productivity and decrease desorbent methanol consumption, continuous process can be obtained by simulating the movement of solids ${ }^{19}$. Continuous reactors with mobile solid phase have been proposed by Cho et al. ${ }^{20}$. However, solid handling in such a reactor is associated with problems such as channelling, abrasion, attrition and fines removal ${ }^{21}$. This drawback can be overcome by simulating the flow of solid counter current to the feed, which is achieved by changing the location of the feed and the product stream points without actual movement of the solid adsorbent and catalyst. SMBR process has been applied to both liquid solid and gas solid phase reactions, where the solid phase implies to solid catalyst-adsorbent. Examples of liquid-solid phase SMBR applications include isomerization of glucose ${ }^{22}$, acetic acid and methanol esterification ${ }^{23}$, 
biotransformations $^{24}$, while one such example of gas-solid phase reaction is the hydrogenation of mesitylene.

A cost-effective production of biodiesel can be achieved using waste raw materials obtained from vegetable and animal origins. However the main problem in the utilization of waste oils is the high concentration of FFA in these oils. The FFA acts as a catalyst poison for the homogeneous alkali catalysts used in the next stage of transesterification ${ }^{25}$. The concentration of FFA should be reduced to $0.5-1 \%$ by weight to ensure adequate conversion in subsequent transesterification reaction ${ }^{25}$. The FFA content of the oils can be removed by esterification of FFA with methanol over solid catalysts to FAME. Hence, a very high conversion of FFA, $>90 \%$, is desired. The aim of the present work is to develop a dynamic simulation model for high and continuous conversion of $F A$ into the production of high purity FAME, which can then be fed to a transesterification unit.

Hilaly $^{7}$ conducted an experimental study for the continuous production of FAME using SMBR. Their system consisted of four zones with 10 SER columns with 5-1-2-2 configuration of columns in zones I (reaction), II (desorption), III (regeneration) and IV (reload), respectively. Each column was packed with resin (Bayer K2629) as a heterogeneous catalyst for conversion of FFA into biodiesel FAME. The resin also acted as a selective adsorbent for water, thereby increasing the conversion to and purity of the biodiesel. However, they have not presented any methodology for systematic realisation of the SMBR process design and operating variables. A SMBR process operation is dependent on various parameters such as length of the bed, flow rate in different sections, ratio of reactants in feed, and switching time etc. The dynamic simulations can provide decision making on process design and operating variables and complement the 
experimentation of such processes. This work presents rigorous dynamic simulation frameworks developed for novel applications to SMBR in high purity FAME production using esterification reactions.

The paper is structured as follows. In the following section, the methodology for dynamic simulation of the fixed bed reactor and SMBR is discussed. The kinetic model developed for esterification reactions to FAME is also illustrated in this section. The subsequent section presents the parametric analyses on the performance of the fixed bed and SMBR processes, followed by the conclusion.

\section{Methodology}

\subsection{Kinetic Modelling of Esterification reaction}

A kinetic model was developed based on the experimental study on heterogeneously catalyzed esterification reaction of palmitic acid $\left(\mathrm{C}_{16} \mathrm{H}_{33} \mathrm{O}_{2}\right)$ dissolved in commercial sunflower oil over silica supported Nafion resin (SAC-13) by Ni and Meunier ${ }^{25}$. A Langmuir-Hinshelwood-Hougen-Watson (LHHW) type of elementary reaction mechanism was assumed (Equation 1). $\mathrm{CH}_{3} \mathrm{OH}, \mathrm{FA}, \mathrm{FAME}, \mathrm{H}_{2} \mathrm{O}$ represent methanol, fatty acid, fatty acid methyl ester, and water in the bulk phase respectively, while $\mathrm{CH}_{3} \mathrm{OH}^{*}, \mathrm{FA}^{*}, \mathrm{FAME}^{*}, \mathrm{H}_{2} \mathrm{O}^{*}$ and $*$ represent their respective adsorbed component on lattice sites and empty lattice sites on the catalyst surface.

Esterification elementary Reactions (LHHW Mechanism) 


$$
\begin{aligned}
& { }_{+} \mathrm{CH}_{3} \mathrm{OH} \Leftrightarrow \mathrm{CH}_{3} \mathrm{OH}^{*} \\
& *+F A \Leftrightarrow F A^{*} \\
& \mathrm{CH}_{3} \mathrm{OH}^{*}+\mathrm{FA}^{*} \Leftrightarrow \mathrm{FAME}^{*}+\mathrm{H}_{2} \mathrm{O}^{*} \\
& \mathrm{FAME}^{*} \Leftrightarrow \mathrm{FAME+*} \\
& \mathrm{H}_{2} \mathrm{O}^{*} \Leftrightarrow \mathrm{H}_{2} \mathrm{O}+*
\end{aligned}
$$

The overall reaction rate expressions were derived based on the assumption that the surface reaction between $\mathrm{CH}_{3} \mathrm{OH}^{*}$ and $\mathrm{FA}^{*}$ in Equation 1-III, is the rate determining step. All other adsorption steps are in equilibrium. In the overall rate expression in Equation $2, K_{1}-K_{5}$ represent the equilibrium rate constants for reactions I-V in Equation 1 respectively; $k_{f}$ represents the forward reaction rate constant of reactions 1-III .

$$
R=\frac{k_{f}\left(K_{1} K_{2}\left[F A \rrbracket\left[\mathrm{CH}_{3} \mathrm{OH}\right]-\frac{K_{4} K_{5}}{K_{3}}[F A M E]\left[\mathrm{H}_{2} \mathrm{O}\right]\right)\right.}{\left(1+K_{1}[\mathrm{FA}]+K_{2}\left[\mathrm{CH}_{3} \mathrm{OH}\right]+K_{4}[F A M E]+K_{5}\left[\mathrm{H}_{2} \mathrm{O}\right]\right)^{2}}
$$

The kinetic data used to derive the model in Equation 2 in this work is based on experimental studies ${ }^{25}$, comprising a mixture of $30 \mathrm{ml}$ of sunflower oil and palmitic acid (10\% wt of palmitic acid) and $9 \mathrm{ml}$ methanol to a batch reactor of $100 \mathrm{ml}$ capacity, with silica-supported Nafion resin as a catalyst. The concentration in the batch reactor is a function of time varying the rate of reaction as shown in Equation 3. This set of ordinary differential equations (odes) is solved by the ode solver, ode 45 , in MATLAB ${ }^{\circledR} 7$ to derive the concentration of component as a function of time. 


$$
\frac{d C_{i}}{d t}=R \quad \forall i \in\left\{F A, F A M E, \mathrm{CH}_{3} \mathrm{OH}, \mathrm{H}_{2} \mathrm{O}\right\}
$$

The kinetic rate constants in Equation 2 were obtained by curve fitting function 'lsqcurvefit' in MATLAB ${ }^{\circledR} 7$. The residual sum of squares (RSSQ) is defined as the objective function to minimize the difference between experimentally observed concentration and that predicted by the model (Equation 4).

$$
\begin{array}{cc}
R S S Q=\sum_{j=1}^{n \text { timencomp }} \sum_{i=1}\left(C_{i}(j)-C_{i}^{\text {exp erimental }}(j)\right)^{2} & \forall i \in\left\{F A, F A M E, \mathrm{CH}_{3} \mathrm{OH}, \mathrm{H}_{2} \mathrm{O}\right\} \\
& \forall j \in\{\text { time points }\}
\end{array}
$$

Table 1 shows the equilibrium rate constants of individual elementary reaction steps in LHHW mechanism along with the forward reaction rate for the surface reaction step III, as predicted by solving Equations 1-4. Figure 1 demonstrates a comparison between the experimental data and the model predicted values of the conversion of FA with respect to time. As evident from Figure 1 and the RSSQ value obtained as 0.0013 , the model closely interprets experimental data. Also the $\chi^{2}$ value of 0.0028 for the model is less than the $1 \%$ confidence limit $(0.02)^{26}$. Hence, the proposed kinetic model is a statistically reliable representation of the experimental data.

Table 1: Kinetic rate constants in LHHW mechanism for esterification of $F A$ to FAME

Figure 1: Prediction of conversion of $F A$ by reaction into FAME 


\subsection{Modelling of SMBR}

The yield and purity of FAME can further be enhanced by simultaneous adsorption of the by-product water inside the unit. The catalyst, cationic resins, can also act as a chromatographic adsorbent with selective adsorption of water. The methanol in excess quantity is used both as a carrier during adsorption cycle and as a desorbent ${ }^{27}$. The rate of transport of different components through the resin is dependent on their adsorption by resin.

A schematic of a SMBR process proposed for biodiesel production is depicted in Figure 2. The system consists of 4 reactor-adsorber units with uniform cross section and length. The whole system can be divided into four zones, for reaction (I), desorption (II), solid regeneration (III), and reload (IV) respectively, as discussed previously. In the proposed SMBR design, each zone consists of one reactor-adsorber unit. There are two incoming streams, $\mathrm{FA}$ plus $\mathrm{CH}_{3} \mathrm{OH}$ feed and $\mathrm{CH}_{3} \mathrm{OH}$ as the desorbent/eluent and two outgoing streams, raffinate $F A M E$ and extract $\mathrm{H}_{2} \mathrm{O}$ respectively. They divide the system into 4 zones as shown in Figure 2.

Figure 2: Schematic of SMBR for FAME Production (Q indicates flowrates in different zones)

The adsorbent (cationic resin) characteristics for this process are based on the work of Yu et al. ${ }^{28}$, as follows. 
$\forall k \in\{$ I,II,III,IV $\}$

The concentration on the surface of the catalyst $\left(q_{i k}\right)$ is the product of the concentration in the bulk $\left(C_{i k}\right)$ and the Henry's constant $\left(H_{i}\right)$ as given by Equation 5. This assumption is only valid for low concentration of components.

This section presents a generic dynamic simulation framework developed for the SMBR. At first, a fixed bed SER of length, $L$, and diameter, $d_{t}$ is considered to develop the transfer equations for each zone. It was assumed that the concentration varies only in axial direction and is constant along the radial direction. The system was considered to be isothermal at $323 \mathrm{~K}$ and therefore, no energy transfer equation was considered. Additionally, a pseudo-homogeneous mixture of catalyst and sorbent with uniform voidage was considered. With these considerations, the material balance for concentration $\left(C_{i k}\right.$ ) of bulk component $i$ in a catalytic-sorbent zone $k$ is a function of axial diffusivity $\left(D_{L i}\right)$ and velocity $\left(u_{k}\right)$, rates of reaction $(R)$ (Equation 2) and sorption $\left(r_{i k}^{a d s}\right)$ and is given as in Equation 6.

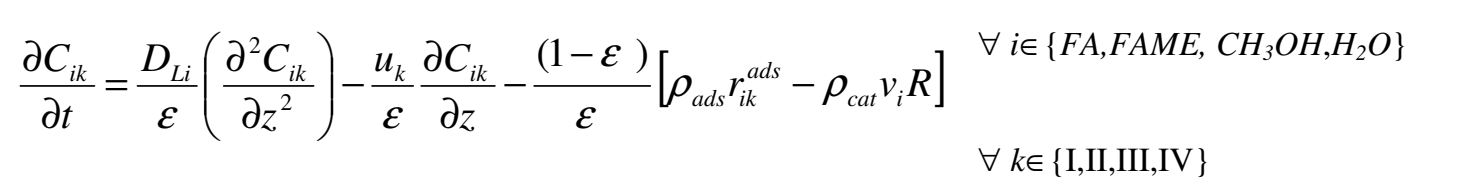

Here, $\rho_{a d s}, \rho_{c a t}, v_{i}$ and $\varepsilon$ are the density of the adsorbent, density of catalyst, stoichiometric coefficient, and porosity in the bed respectively. The rate of adsorption is 
given by the change in the concentration of component $i$ in zone $k$ in the adsorbed phase $\left(q_{i k}\right)$ (Equation 7).

$$
r_{i k}^{a d s}=\frac{d q_{i k}}{d t}
$$

Boundary conditions are obtained from Danckwert's Boundary Conditions ${ }^{29}$. It is assumed that the molar flow into a catalytic-sorbent zone by convection is equal to the diffusion at the inlet of the zone, and there is no change in the concentration at the outlet of each catalytic-sorbent zone (Equation 8(a) and 8(b) respectively).

$$
\begin{array}{ll}
\left(\varepsilon D_{L i} \frac{\partial C_{i k}}{\partial z}\right)_{z=0}=u_{k}\left(C_{i k}^{f}-C_{i k}\right) & \forall i \in\left\{F A, F A M E, \mathrm{CH}_{3} \mathrm{OH}, \mathrm{H}_{2} \mathrm{O}\right\} \\
& \forall k \in\{\mathrm{I}, \mathrm{II}, \mathrm{III}, \mathrm{IV}\} \\
\left(\frac{\partial C_{i k}}{\partial z}\right)_{z=L}=0 &
\end{array}
$$

Furthermore, to simplify the analysis of the modelling results, $\alpha, \beta$ and $\gamma$ are introduced representing the ratios of the flow rates of feed, raffinate and eluent, indicated by $F, R a$ and $E$ respectively, to the flow rate in the reaction zone $\left(Q_{I}\right)$ (Figure 2) (Equation 9).

$$
\begin{gathered}
\alpha=\frac{F}{Q_{I}} \\
\beta=\frac{R a}{Q_{I}}
\end{gathered}
$$




$$
\gamma=\frac{E}{Q_{I}}
$$

The inlet feed concentration and the flow rate in each zone can then be converted in terms of the additional variables $\alpha, \beta, \gamma$ introduced in Equation 9, as shown in Equation $10-16$.

Reaction Zone I (Feed inlet port)

The input feed concentration to the zone 1 in Figure 2 is a combination of the outlet concentration from the previous zone $\left.C_{i(k-1)}\right|_{Z=L}$ and the feed concentration to the SMBR process $\left(C_{i}^{f}\right)$, which can be correlated using the ratio of the feed flow rate to the flow rate in the reaction zone $(\alpha)$.

$$
\begin{array}{cl}
C_{i k}^{f}=\left.(1-\alpha) C_{i(k-1)}\right|_{Z=L}+\alpha C_{i}^{f} & \forall i \in\left\{F A, F A M E, \mathrm{CH}_{3} \mathrm{OH}, \mathrm{H}_{2} \mathrm{O}\right\} \\
& \forall k \in\{\mathrm{I}, \mathrm{II}, \mathrm{III}, \mathrm{IV}\}
\end{array}
$$

\section{Desorption Zone II (Raffinate output port)}

An output raffinate stream is removed from the junction between Reaction zone I and Desorption zone II (Figure 2). Hence, the flow rate in zone II is a fraction of the flow rate from the previous zone $\mathrm{I}$, after a removal of the raffinate flow rate accounted by $\beta$. The concentration in the feed input to zone II is the same as the outlet concentration from the previous zone I.

$$
\begin{array}{ll}
Q_{I I}=(1-\beta) Q_{I} & \forall i \in\left\{F A, F A M E, \mathrm{CH}_{3} \mathrm{OH}, \mathrm{H}_{2} \mathrm{O}\right\} \\
C_{i k}^{f}=\left.C_{i(k-1)}\right|_{Z=L} & \forall k \in\{\mathrm{I}, \mathrm{II}, \mathrm{III}, \mathrm{IV}\}
\end{array}
$$


The feed to zone III is a mixture of eluent and the outlet stream from the zone II. The concentration of the feed thus is the ratio of the flow rate from the previous zone to the overall flow rate including the eluent flow rate.

$$
\begin{array}{ll}
Q_{I I I}=(1-\beta+\gamma) Q_{I} & \forall i \in\left\{F A, F A M E, \mathrm{CH}_{3} \mathrm{OH}, \mathrm{H}_{2} \mathrm{O}\right\} \\
C_{i k}^{f}=\left.\frac{(1-\beta)}{(1-\beta+\gamma)} C_{i(k-1)}\right|_{Z=L} & \forall k \in\{\mathrm{I}, \mathrm{II}, \mathrm{III}, \mathrm{IV}\}
\end{array}
$$

Reload Zone IV (Extract take-off port and the rest of the units)

A part of the outlet from section III is gathered as an extract with a high concentration of the secondary product. The outlet from zone IV is fed to zone I. Hence the flow rate in this section is calculated by subtracting the feed flow rate from the flow rate in zone I. The concentration of the feed to zone IV is equal to the output from the zone III.

$$
\begin{array}{ll}
Q_{I V}=(1-\alpha) Q_{I} & \forall i \in\left\{F A, F A M E, \mathrm{CH}_{3} \mathrm{OH}, \mathrm{H}_{2} \mathrm{O}\right\} \\
C_{i k}^{f}=\left.C_{i(k-1)}\right|_{Z=L} & \forall k \in\{\mathrm{I}, \mathrm{II}, \mathrm{III}, \mathrm{IV}\}
\end{array}
$$

At the end of a switching time $\left(t_{s}\right)$ the inlet (Feed, Eluent) and outlet (Raffinate, Extract) ports are moved ahead in the direction co-current to the flow of the liquid, by one catalytic-sorbent zone. Hence a relative movement of solid is simulated counter current to the flow of the liquid. The initial condition after every port switching remains the same as the final concentration profile before the port switch. 


\section{Parametric sensitivity analysis}

SMBR is a complex operation and its precise design requires decisions on switching time, flow rates in different sections, and feed concentrations as input parameters. The aim of this work is to determine such combinations of operating parameters for a high conversion of reactants and separation between products. Literature has shown some methodologies that utilize the analogy of SMBR with simulated moving bed (SMB) operation without reaction, for deciding the flow rates in different sections ${ }^{23,30,31}$. Even though a true counter current (TCC) between solid and liquid phases is difficult to realize, SMB processes can be modelled based on a TCC design. The relative flow rate of the solid in SMB can be converted to an equivalent flow rate in TCC $\left(Q^{T C C, s}\right)$ as shown in Equation 17. $Q_{k}^{T C C}$ refers to the flow rates of liquid in a TCC process, while $Q_{k}^{S M B}$ refers to the flow rate in SMB in zone $k$. Dimensionless parameter $m_{k}$ can further be defined as the ratio between the net flow rate of liquid and solid in $k^{\text {th }} \mathrm{zone}^{30}$.

$$
\begin{aligned}
& Q^{T C C, s}=\frac{(1-\varepsilon) V_{c o l}}{t_{s}} \\
& Q_{k}^{T C C}=Q_{k}^{S M B}-\frac{\varepsilon V_{c o l}}{t_{s}} \\
& m_{k}=\frac{Q_{k}^{T C C}-\varepsilon Q^{T C C, s}}{(1-\varepsilon) Q^{T C C, s}} \quad \forall k \in\{\text { I,II,III,IV }\}
\end{aligned}
$$

Here, $V_{c o l}$ is the volume of each column, $\varepsilon$ is the porosity of the bed, while $t_{s}$ is the switching time for the shift of the ports. 
Lode et al..$^{30}$ developed Equations 20-22 as a set of conditions for an initial estimate of flow rates in each zone. The objective of a SMBR process is to achieve nearly complete separations between products and high purity and yield of products. In order to prevent FAME from reaching the extract outlet, the ratio of flow rates in zone $\mathrm{I}\left(m_{I}\right)$ and zone IV $\left(m_{I V}\right)$ must be greater than the Henry's constant of FAME as shown in Equation 21. Similarly if the flow rate ratio in zone $\mathrm{I}\left(m_{I}\right)$ is greater than the Henry's constant of water, the concentration of water in the raffinate phase would be higher, which is not desirable. The flow rate in zone IV is a fraction of the flow rate in zone I as given by Equation 15. Since the pseudo solid flow rate is constant in all zones depending only on the switching time, the flow rate in zone $\mathrm{I}\left(m_{I}\right)$ is always greater than the flow rate in zone IV $\left(m_{I V}\right)$. The flow rate ratio in zone III $\left(m_{I I I}\right)$ and zone II $\left(m_{I I}\right)$ is limited by the Henry's constant of water and FAME as shown in Equation 20 and 22 respectively.

$$
\begin{aligned}
& m_{I I I}>H_{H_{2} \mathrm{O}} \\
& H_{\mathrm{H}_{2} \mathrm{O}}>m_{I}>m_{I V}>H_{F A M E} \\
& H_{\text {FAME }}>m_{I I}
\end{aligned}
$$

Figure 3 shows the operating region of conversion using the constraints given in Equations 20-22. The flow rate ratios have been obtained by keeping the switching time $\left(t_{s}\right), \beta$ and $\gamma$ constant as $600 \mathrm{~s}, 0.49,0.75$ respectively $^{7}$. The flow rate in the feed zone $\left(Q_{I}\right)$ is changed from $5 \times 10^{-4}$ to $7 \times 10^{-4} \mathrm{~m} / \mathrm{s}$, while $\alpha$, the ratio of the flow rates of the feed and in the zone I, is varied between 0.1 and $0.2^{7}$. Further changes in these two parameters 
lead to the points outside the triangle region in the graph. The Henry's constants and all

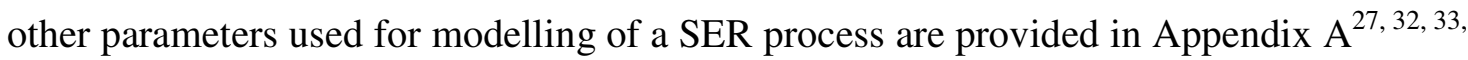
34,35

Figure 3: Operating parameters for FAME synthesis by SMBR as represented on the flow ratio $m_{I}-m_{I V}$ parameter plane for a given residence time. * represents the operating points.

The application of the above theory based on the TCC flow (Equations 20-22) allows us to estimate initial flow rates in different sections. However, the model assumes no mass transfer limitations, infinite dilution for the Henry's law to be valid and true counter current. Additionally, the equilibrium models cannot directly link purity of the products to the process parameters such as flow rates, switching time etc., for a SMBR process ${ }^{36}$. Hence the lower bounds of the flowrates determined using these correlations can only represent their respective minimum limits, for a more rigorous parametric analysis. In this work, the effect of operating conditions such as the flow rates in different zones and the switching time, on the purity and conversion is studied in detail in the next section.

\section{Evaluation of performance of SMBR}

The purity and conversion are used as the basis for evaluating the performance of a SMBR process under different operating conditions. Purity is defined as the ratio of the concentration of FAME in the raffinate to the overall concentration of the raffinate on a methanol free basis. Purity is a very important desirable variable from a SMBR unit 
producing biodiesel, as the raffinate obtained from this unit can be a feed to the transesterification reactor.

$$
\begin{aligned}
& \text { Purity }=\frac{F A M E_{\text {raffinate }}}{\left(F A M E+H_{2} O+F A\right)_{\text {raffinate }}} \\
& =\frac{\int_{0}^{t_{s}{ }^{*} N_{c}} C_{F A M E}^{r} d t}{\left(\int_{0}^{t_{s}{ }^{*} N_{c}} C_{F A M E}^{r} d t+\int_{0}^{t_{s}{ }^{*} N_{c}} C_{F A}^{r} d t+\int_{0}^{t_{s}{ }^{*} N_{c}} C_{H_{2} O}^{r} d t\right)}
\end{aligned}
$$

Conversion of a SMBR process is described as the ratio of the $F A$ converted to the $F A$ entering to the process. The $F A$ converted in the process is defined as the difference between the $F A$ entering as a feed to the process and the $F A$ leaving the process through the raffinate and the extract streams. The $F A$ content is usually $10 \%$ by weight in the used vegetable oil $^{7}$. The concentration of $F A$ in the feed to the transesterification reactor should be reduced to $0.5-1 \%$ to avoid catalyst poisoning ${ }^{25}$. Hence it is essential to have greater than $90 \%$ conversion of $F A$ in the feed stream to SMBR.

$$
\begin{aligned}
& \text { Conversion }=\frac{\left(F A_{\text {feed }}-F A_{\text {raffinate }}-F A_{\text {extract }}\right)}{F A_{\text {feed }}} \\
& =\frac{\left(\alpha C_{F A}^{f} * t_{s} * N_{c}-\left(\beta \int_{0}^{t_{s}^{*} N_{c}} C_{F A}^{r} d t+(\alpha-\beta+\gamma) \int_{0}^{t_{s}^{*} N_{c}} C_{F A}^{e} d t\right)\right)}{\alpha C_{F A}^{f} * t_{s} * N_{c}}
\end{aligned}
$$

\section{Solution strategy}

The partial differential Equations 6-8 (PDEs) were converted to ordinary differential equations (ODEs) by the method of lines. Central finite difference scheme was used to discretize the concentration profiles at all the grid points. The inlet (Feed and Eluent) and outlet (Raffinate and Extract) conditions in each catalytic-sorbent zone are provided in 
Equations 10-16. At the end of the first switching cycle $\left(t_{s}\right)$, the reactor units $1,2,3$, and 4 operate as reload (IV), reaction (I), desorption (II) and regeneration (III) zones, respectively. Hence, the feed to these zones is changed accordingly. The simulations are continued with the feed conditions obtained from a previous cycle, for each zone. Similarly, all other conditions in a zone at the end of a switching are imposed as initial conditions for the next port switch.

\section{Algorithm for the dynamic simulation framework for SMBR}

The algorithm for SMBR can be described as

- For a given $C_{i k}$ at the initial time and the parameters such as axial diffusivities, flow rates etc., provided in the Appenedix A, the feed flow rates in differenet zones were predicted using Equations 10-16.

- The bulk concentration along the length was discretized to calculate the value of $\frac{d C_{i k}}{d t}$ (Equation 6).

- The resulting equations were solved by ode15s solver in MATLAB over time 0$\mathrm{t} s$ with a time gap of $1 \mathrm{~s}$.

- The simulation was repeated with the inlet and outlet ports advanced by one catalytic-sorbent zone length in the direction co-current to the direction of the flow. The initial concentration in the units remained the same as the final concentration from the previous switch. 
- Bulk scale parametric sensitivity analysis was carried out with respect to various decision variables such as switching time, bed voidage, length of the bed, velocity etc. illustrated in the following section. The trapezoidal rule for the integration of the concentration profile over time was applied for the calculation of the purity and conversion as a common basis for comparison between performances (Equations 23-24 respectively).

\section{Results and Discussions}

\subsection{Fixed bed SER}

The outlet concentration vs time profiles for a SER were obtained by solving Equations 5-8 and using parameters provided in Table 1 and Appendix A (Figure 4). The conditions for this system are $u=0.0002 \mathrm{~m} / \mathrm{s}, L=0.1 \mathrm{~m}$ and $\mathrm{CH}_{3} \mathrm{OH} / \mathrm{FA}$ ratio of 5 . The initial time up to 500s with no output (Figure 4), is the residence time, which is the time taken by the feed stream to reach the outlet port of the SER. The output from the reactor initially contains the weakly adsorbed component, pure FAME with $85 \%$ purity. The simultaneous reaction-sorption continues until the resin in the SER is completely saturated with water for the SER. The time point corresponding to 1000s in Figure 4 is called the breakthrough point, beyond which the adsorption capacity of the SER bed is exhausted. The unconverted $\mathrm{FA}$ and $\mathrm{H}_{2} \mathrm{O}$ along with excess $\mathrm{CH}_{3} \mathrm{OH}$ are released from the SER after the breakthrough point. At the same time, the concentration of FAME is decreased after the sorption capacity of the bed is exhausted. The outlet composition remains constant after 2500s, which indicates the equilibrium point. The difference in the area under the curve 
between $F A M E$ and $\mathrm{H}_{2} \mathrm{O}$ concentration profiles corresponds to the adsorptive capacity of the bed which is $9.07 \mathrm{~mol} / \mathrm{m}^{3}$.

Figure 4: Outlet concentration from fixed bed chromatographic reactor producing FAME from FA esterification, $u=2 \times 10^{-4} \mathrm{~m} / \mathrm{s}, L=0.1 \mathrm{~m}$ and $\mathrm{CH}_{3} \mathrm{OH} / F A=5$

\section{Effect of parameters on performance of SER}

The effects of the parameters, length of the bed, velocity through the bed and the molar ratio of $\mathrm{CH}_{3} \mathrm{OH}$ and $\mathrm{FA}$, on the performance of the fixed bed SER under consideration are analysed in the following section.

\section{Effect of length of the bed}

The effect of the change in the bed length from $0.25 \mathrm{~m}$ and $0.5 \mathrm{~m}$ on the outlet mole fraction profile, in a fixed bed SER, is shown in Figure 5. The other parameters were kept same as provided in Appendix A. The increase in length while keeping the velocity constant, increases the residence time inside the reactor, thereby increasing the starting point of FAME production from 500 to 1000 s. Additionally the unit was found to produce high purity FAME for a longer duration of time with increase in length. The times taken to production of the pure $F A M E$, devoid of $F A$ and $\mathrm{H}_{2} \mathrm{O}$, for a length of 0.25 $\mathrm{m}$ and $0.5 \mathrm{~m}$ are $500 \mathrm{~s}$ and $1500 \mathrm{~s}$ respectively due to the increase in the adsorption capacity of the bed with the increase in the length of the bed. The trade-off is between 
obtaining high purity FAME for a longer duration and the increased capital investment. Apart from that, there is no change in the equilibrium concentration profiles.

Figure 5: Outlet concentration from a fixed bed chromatographic reactor for different lengths of the bed $\left(u=0.0002 \mathrm{~m} / \mathrm{s}, \mathrm{CH}_{3} \mathrm{OH} / F A=15.0\right)$

\section{Effect of superficial velocity}

Two superficial velocities of $2 \times 10^{-4} \mathrm{~m} / \mathrm{s}$ and $1 \times 10^{-4} \mathrm{~m} / \mathrm{s}$ through the fixed bed SER were selected, while keeping the other parameters same as given in Appendix A, to investigate their effects on the outlet concentration profiles as shown in Figure 6. The decrease in velocity for a constant bed length increases the residence time of FAME in the SER unit from 500s (500-1000 s) to 1000s (1000-2000 s), respectively in Figure 6. Hence, this is the time, when pure $F A M E$, free from $F A$ and $\mathrm{H}_{2} \mathrm{O}$, is obtained from the SER. The same adsorption capacity of the bed can be used for a longer period of time for smaller velocities as shown in Figure 6.

Figure 6: Outlet concentration from a fixed bed chromatographic reactor for different superficial velocities $\left(L=0.5 \mathrm{~m}, \mathrm{CH}_{3} \mathrm{OH} / F A=15.0\right)$

\section{Effect of Feed ratio}


Two different $\mathrm{CH}_{3} \mathrm{OH}$ to $\mathrm{FA}$ molar ratios of 5:1 and $15: 1^{37}$ were investigated while keeping the other parameters same as in Appendix A. The effect of the change in feed ratio on the outlet concentration profiles is presented in Figure 7. The FA concentration in the feed to the SER was kept the same in these simulations, while the methanol concentration was increased according to the molar ratio of $\mathrm{CH}_{3} \mathrm{OH}$ to $\mathrm{FA}$. The initial highest mole fraction of $F A M E$ is 0.8 for a $\mathrm{CH}_{3} \mathrm{OH} / \mathrm{FA}$ molar ratio of 5, while it is 0.82 for a $\mathrm{CH}_{3} \mathrm{OH} / \mathrm{FA}$ molar ratio of 15 , respectively. This increase in the initial mole fraction at the outlet is attributed by the increase in the reaction rate due to the presence of excess quantity of one of the reactants, in this case methanol. The equilibrium mole fraction for FAME is 0.55 and 0.4 for $\mathrm{CH}_{3} \mathrm{OH} / \mathrm{FA}$ molar ratios of 5 and 15 , respectively. Any increase in one of the reactants (methanol) increases the equilibrium conversion of the limiting reactant $(F A)$, resulting from a shift in equilibrium to the right, according to Le Chatelier's principle. The equilibrium conversion for the limiting reactant $F A$ decreases from $71 \%$ to $55 \%$, as $\mathrm{CH}_{3} \mathrm{OH} / \mathrm{FA}$ molar ratio is reduced from 15 to 5 , beyond which the conversion is too low to take into account.

Figure 7: Outlet concentration from a fixed bed chromatographic reactor for different $\mathrm{CH}_{3} \mathrm{OH} / \mathrm{FA}$ ratio $\left(L=0.5 \mathrm{~m}, u_{I}=1 \times 10^{-4} \mathrm{~m} / \mathrm{s}\right)$

In the previous section, the production of FAME with greater than $80 \%$ purity from a fixed bed SER was demonstrated. However, this system can only be used for a small batch time for the production of high purity FAME, before the bed is exhausted. The 
continuous production of FAME is feasible by regenerating the SER. There is a high concentration of FAME inside the SER unit at the end of a production cycle as seen by the outlet concentrations in Figure 7. This amount of FAME may be lost during the regeneration of the bed by the eluent methanol. Hence, continuous production by the regeneration of the bed can lead to a loss of FAME in the regeneration step. This can be avoided by the use of a SMBR, investigated in the following section. The products water and FAME can be completely separated, by a combination of four SER units in each of the four zones, as depicted in Figure 2.

\subsection{SMBR}

The mathematical model for a fixed bed SER in Equations 5-8 is used to predict the performance of a single reactor-adsorber unit in a SMBR. Each reactor-adsorber unit in a zone is divided into 80 discrete finite difference points. No further improvement in the accuracy and convergence of the results with more than 80 finite difference points was observed. The base conditions for this system are same as that presented in Appendix A. Figure 8 shows the concentration profile along the length of the unit after 4 feed port switches. For the given cycle in Figure 8, the feed to the reactor-adsorber unit 1 (reaction zone) contains a mixture of fresh feed and the outlet from the reactor-adsorber unit 4 . The fresh feed was a mixture of methanol and $F A$. In the previous cycle, reactor-adsorber unit 4 was used for the reaction to FAME. Hence this unit still has some amounts of FAME, $\mathrm{H}_{2} \mathrm{O}$ and $F A$, flowing to reactor-adsorber unit 1. The addition of $F A$ through the fresh feed to the flow from reactor-adsorber unit 4 increases the concentration of $F A$ in reactoradsorber unit 1. This further increases the amount of FAME in the raffinate stream. 
Therefore, high concentration of FAME in the raffinate stream is obtained $\left(1.3 \mathrm{~mol} / \mathrm{m}^{3}\right.$ with purity $75.5 \%$ ). The removal of a part of a raffinate from the outlet of reactoradsorber unit 1 decreases the flow rate into unit 2 (Equation 11). The decrease in flow rate lowers the convective flow into the unit (Equation 6) and hence there is a decrease in the concentration along the axis in unit 2 (Figure 8). The inlet to reactor-adsorber unit 3 is made up of eluent methanol and the outlet stream from unit 2 (Equation 14), leading to a decrease in concentration of the feed to the unit 3 as shown in Figure 8. The water is adsorbed into the resin of reactor-adsorber units 2 and 3 in the previous feed port switches due to the higher adsorption Henry's constant (Appendix A). The extract stream is predominantly made up of water as this water is desorbed by eluent methanol, into the extract phase (Figure 8).

Figure 8: Concentration profile along the length of the SMBR after four feed port switches $\left(t_{s}=600 \mathrm{~s}, L=0.25 \mathrm{~m}, u_{I}=2.4 \times 10^{-4} \mathrm{~m} / \mathrm{s}\right)$

Figure 9 shows the raffinate concentration profiles of the stream for four consecutive feed port switches, started with inlet-outlet port switches shown in Figure 8. Initially there is a time gap to see any outlet products from the reactor to the raffinate corresponding to the residence time of the streams in a reactor-adsorber unit. Thereafter, FAME obtained in the raffinate phase is almost pure (with no feed port switch and between 400 and 600s in Figure 9). However as the number of feed port switches increases, the purity of FAME in the raffinate may fall (feed port switch 3 and after 1800s), due to incomplete regeneration of the used catalytic-sorbent beds. A SMBR unit can be regenerated to produce pure products by proper use of operating conditions. 
Hence, in the next section the effect of operating conditions on the performance of the SMBR is investigated.

Figure 9: Raffinate Mole Fraction for four feed port switches $\left(t_{s}=600 \mathrm{~s}, L=0.25 \mathrm{~m}\right.$, $\left.u_{I}=2.4 \times 10^{-4} \mathrm{~m} / \mathrm{s}\right)$

\section{Effect of operating conditions on performance of SMBR}

The effect of parameters such as switching time $\left(t_{s}\right)$, length of the bed, and flow rates in desorption, regeneration and reload zones on the purity and conversion from the SMBR process (Equations 23 and 24 respectively) is discussed in this section. The values of the parameters are increased from the minimum values obtained from the TCC analysis (Equations 20-22), and the purity and conversion are noted after 4 port switches.

\section{Effect of Switching Time}

The effect of switching time $\left(t_{s}\right)$ on the performance of the SMBR process, as measured in terms of conversion and purity, was studied by varying the switching time from $600 \mathrm{~s}$ to 1200 s, while other parameters were kept constant (Table 2). As illustrated in Table 2, the increase in residence time decreases the conversion of FA from $92.64 \%$ to $89.43 \%$, while the purity initially increases from $75.51 \%$ to $80.89 \%$ and then decreases to $77.49 \%$. The increase in switching time decreases the pseudo velocity of the solids. If the switching time is low, FAME would not have enough time to desorb from zone I and be 
collected with the raffinate phase and instead would be extracted with the extract phase. The reduction in residence time also affects the efficiency of the regeneration zone and reload zone, III and IV respectively. For low switching times the regeneration of the bed is not complete, hence the purity of the raffinate is lower. If the switching time is too high, increase in water in the raffinate decreases the purity of FAME. Thus, an optimal switching time of $900 \mathrm{~s}$ is ideal in terms of purity of FAME in the raffinate phase providing a conversion of $90.95 \%$ and purity of $80.89 \%$ (Table 2). Increase in switching time initially increases and then decreases the purity, due to the time of desorption of FAME and water respectively. The regeneration of the adsorbent is an important process for proper utilization of the switching time of the system. Another important factor that can be used for the regeneration of a spent bed is by complete purge of the bed by increasing the flow rate of the eluent.

\section{Effect of Length of the reactor-adsorber unit}

The increase in length of the reactor-adsorber unit from $0.25 \mathrm{~m}$, through $0.5 \mathrm{~m}$ to $1.0 \mathrm{~m}$ drastically reduces the purity of FAME from $75.51 \%$ to $33.33 \%$ and gradually decreases the conversion from $92.64 \%$ to $88.25 \%$ as provided in Table 2. An increase in length increases the residence time in the reactor-adsorber unit in comparison to the pseudo flow rate of the solid adsorbent. When the length of the reactor-adsorber unit is higher, FAME in zone I doesn't reach the raffinate outlet point before the switching time. Additionally, due to the higher time taken by the eluent to pass through the system in comparison to the switching time, the regeneration of the bed in zone IV is also not complete, hence the purity of the raffinate is lower. The residence time can be kept constant by increasing the 
length and correspondingly increasing the velocity through the bed. However, even this case can lead to a decrease in purity due to the increase in the amount of reactants without increasing the capacity of the bed, as was also evident from the analysis of the fixed bed SER. A length of $0.25 \mathrm{~m}$ was found to be appropriate, with combinations of other operating conditions provided in Table 2.

\section{Effect of flow rate in reload zone $\alpha$}

To investigate the effect of the flow rate in the reload zone on the performance of SMBR process, $\alpha$ was varied from 0.1 to 0.6 (Equation 15 ), while the other parameters were kept same as evident from Table 2 . The increase in $\alpha$ increases the purity of the system from $76.14 \%$ to $77.96 \%$, while the conversion decreases from $94.70 \%$ to $90.26 \%$ as shown in Table 2. As shown in Equation 9, if the feed flow rate is kept constant, the increase in $\alpha$ decreases the flow rate in zone I as well as in all other sections (Equations 11,13 and 15). A decrease in the flow rate for a given feed concentration reduces the rate of reaction due to the lesser amount of reactants, leading to a fall in the conversion. However, decrease in flow rate increases the residence time $\left(t_{s}\right)$ and the time of separation in zones II, III and IV. The net effect is the increase in the purity of the raffinate.

\section{Effect of flow rate of raffinate $\beta$}

The effect of the flow rate of raffinate on the performance of the SMBR process was studied by varying $\beta$ from 0.1 to 0.5 (Equation 11 ), with other parameters kept constant as revealed in Table 2 . With the increase in $\beta$, the purity of the system initially decreases 
from $77.9 \%$ to $75.51 \%$ and then increases to $77.28 \%$, while the conversion initially increases from $91.76 \%$ to $92.64 \%$ and then decreases to $92.18 \%$. The increase in $\beta$, decreases the flow rate through desorption and regeneration zones (Equation 11 and Equation 13), along with a decrease in recycle. Firstly, the increase in raffinate flow decreases the purity, but leaves unutilized reactor-adsorber beds, which improves the conversion. With increasing raffinate flow as the conversion reaches to a maximum, when an available set of beds is completely utilized, the purity starts increasing from a minimum. But increasing purity leaves lesser capacity of the beds, which lowers the conversion in turn.

\section{Effect of flow rate of eluent $\gamma$}

The effect of the flow rate of eluent, or $\gamma$ from 0.75 to 1.5 (Equation 13) on the performance of a SMBR process is opposite to what's been observed for $\beta$, presented in Table 2. The increase in $\gamma$ initially increases the purity from $75.51 \%$ to $77.85 \%$ along with a subsequent decrease to $77.40 \%$, while conversion initially decreases from $92.64 \%$ to $92.18 \%$ and then increase to $93.07 \%$ as shown in Table 2 . There are two opposing factors affecting the purity with the increase in desorbent flow rate $\gamma$. The increase in desorbent flow rate increases the flow rate in the regeneration zone III as obvious from Equation 13 . The reactor adsorbed unit 3 in zone III can be completely regenerated by increasing the flow rate of the eluent, thus providing higher purity products. However with further increase in the eluent flow rate, the concentration of water in the feed to zone IV and thereby to zone I increases, which in turn reduces the purity from SMBR. Therefore, a maximum in the purity at $77.85 \%$ was observed. As expected, the effect of 
increasing $\gamma$ on the conversion is opposite than the effect on the purity, presenting a minimum in the former.

Table 2: Effect of parameters on the performance of SMBR

In Table 2, there's a set of operating conditions, marked by *, that corresponds to greater than $90 \%$ conversion of $F A$ into FAME. These operating conditions thus can be used to design SMBR for esterification reaction of used vegetable oils into FAME, feeding to transesterification reaction.

The effect of the design and operating variables on the SER and SMBR process performance is summarised in Table 3. With increasing length of a SER bed or reduction in superficial velocity, high purity FAME can be produced from the SER for a longer time duration, due to increasing residence time. Conversion and purity from a SER can also be increased by increasing the feed ratio due to the shift in equilibrium concentration. While such results from performance analysis of a SER are expected, SMBR processes displayed a complex behaviour including maximum and minimum in purity and conversion, which have made this simulation task worthwhile. With increasing switching time the conversion in a SMBR process can be increased and a maximum purity of biodiesel can be achieved. A maximum purity of $80.89 \%$ and a conversion of $90.95 \%$ are obtained for the switching time of 900s. Increase in length can drastically reduce the purity due to the insufficient time for feed to reach the outlet port and incomplete regeneration of the used bed. The decrease in flow rate in zone $\mathrm{I}, \alpha$, reduces the reaction rate and hence the conversion, while it increases the purity due to complete 
separation of water by adsorption. The conversion shows a maximum, while purity has a minimum with increasing $\beta$ (or raffinate flow rate), due to the two opposing effects of the amount of recycle and utilization of reactor-adsorber beds. Furthermore, a maximum in purity and a minimum in conversion with the increase in eluent flow rate were observed. The complete regeneration of the reactor-adsorber unit increases the purity, while the effect on the conversion is reverse due to the increased concentration of water in the feed.

Table 3: Summary of the effect of design and operating parameters on the performance of SER and SMBR

\section{Conclusions}

This work investigates into the synthesis of FAME by SER and SMBR processes using rigorous dynamic simulation approaches. The simulation frameworks were developed to analyse the effect of various design and operating parameters such as length and velocity of the bed, feed ratio, flowrate ratios in different zones in case of the SMBR, on the feed conversion and outlet concentration / purity. The continuous production of pure FAME was designed by simulating the movement of solid catalyst and adsorbent bed through switching inlet and outlet fluid ports, in a SMBR process. The lower limit of the acceptable flow rates for the SMBR process was determined by a comparison with a true counter current system. The rigorous dynamic simulation of the SMBR process further helped to investigate the effect of various operating parameters such as switching time, length of the reactor-adsorber unit, flow rate in desorption zone, solid regeneration and 
reload zone on the purity of the raffinate and the conversion of $F A$. The purity of FAME and conversion of $F A$ are taken as the two main criteria to compare the performances amongst different sets of operating conditions. The conversion of feed into and purity of product from a SMBR process may display competing objectives, although in narrow ranges of operating conditions. Henceforth, dynamic simulation tool provides a useful mechanism for a systematic decision making of optimal operating conditions,

\section{Acknowledgement:}

Financial support from EPSRC (EP/D04829X/1) of the UK for undertaking this research is gratefully acknowledged.

\section{Nomenclature}

$C_{i}(t) \quad$ concentration in a batch reactor at time $t, \mathrm{~mol} / \mathrm{m}^{3}$

$C_{i}^{\text {experimental }}(t)$ experimental concentration in batch reactor at time $t, \mathrm{~mol} / \mathrm{m}^{3}$

$C_{i}^{f} \quad$ feed concentration of component $i$ to SMBR, $\mathrm{mol} / \mathrm{m}^{3}$

$C_{i k}^{f} \quad$ feed concentration of component $i$ to zone $k, \mathrm{~mol} / \mathrm{m}^{3}$

$C_{i}^{r} \quad$ concentration of component $i$ in raffinate, $\mathrm{mol} / \mathrm{m}^{3}$

$C_{i}^{e} \quad$ concentration of component $i$ in extract, $\mathrm{mol} / \mathrm{m}^{3}$ 


\begin{tabular}{|c|c|}
\hline$C_{i k}$ & concentration of component $i$ in zone $k, \mathrm{~mol} / \mathrm{m}^{3}$ \\
\hline$C_{i k}^{i c}$ & initial concentration of component $i$ in zone $k, \mathrm{~mol} / \mathrm{m}^{3}$ \\
\hline$\left[\mathrm{CH}_{3} \mathrm{OH}\right]$ & activity of methanol, $\mathrm{mol} / \mathrm{m}^{3}$ \\
\hline$D_{L i}$ & axial diffusion coefficient for component $i, \mathrm{~m}^{2} / \mathrm{s}$ \\
\hline$d_{p}$ & diameter of particle, $\mathrm{m}$ \\
\hline$d_{t}$ & diameter of tube, $m$ \\
\hline E & flow rate of eluent, $\mathrm{m}^{3} / \mathrm{s}$ \\
\hline$F$ & flow rate of feed, $\mathrm{m}^{3} / \mathrm{s}$ \\
\hline$[F A]$ & activity of fatty acid, $\mathrm{mol} / \mathrm{m}^{3}$ \\
\hline [FAME] & activity of fatty acid methyl ester, $\mathrm{mol} / \mathrm{m}^{3}$ \\
\hline$\left[\mathrm{H}_{2} \mathrm{O}\right]$ & activity of water, $\mathrm{mol} / \mathrm{m}^{3}$ \\
\hline$H_{i}$ & Hernry's constant for adsorption for component $i$, dimensionless \\
\hline$K_{p}$ & $\begin{array}{l}\text { equilibrium kinetic rate constants for elementary step } p \text { in LHHW } \\
\text { mechanism }\end{array}$ \\
\hline$k_{f}$ & forward reaction rate constant, $\mathrm{mol} \mathrm{m} \mathrm{m}^{-3} \mathrm{~s}^{-1}$ \\
\hline$k_{a d s, i}$ & rate constant of sorption, $\mathrm{mol} \mathrm{kg}^{-1} \mathrm{~s}^{-1}$ \\
\hline$L$ & length of the SER, $\mathrm{m}$ \\
\hline
\end{tabular}


nrxn

total number of reactions, dimensionless

ntime

no of time points, dimensionless

$N_{c}$

number of cycles, dimensionless

$q_{i k}^{*}$

equilibrium solid phase concentration for component $i$ in zone $k, \mathrm{~mol} / \mathrm{kg}$

$q_{i k} \quad$ solid phase concentration for component $i$ in zone $k, \mathrm{~mol} / \mathrm{kg}$

$Q^{T C C, s} \quad$ flow rate of solid for true counter current, $\mathrm{m}^{3} / \mathrm{s}$

$Q_{k}^{T C C} \quad$ flow rate of liquid for true counter current in zone $k, \mathrm{~m}^{3} / \mathrm{s}$

$Q_{k}^{S M B} \quad$ flow rate of liquid for SMB in zone $k, \mathrm{~m}^{3} / \mathrm{s}$

$Q_{k} \quad$ flow rate in zone $k, \mathrm{~m}^{3} / \mathrm{s}$

$R a \quad$ flow rate of raffinate, $\mathrm{m}^{3} / \mathrm{s}$

$R \quad$ reaction rate in a batch reactor, $\mathrm{mol} / \mathrm{kg}-\mathrm{s}$

$R S S Q \quad$ residual sum of squares, $\mathrm{mol} \mathrm{m}^{-3}$

$r_{i k}^{a d s} \quad$ rate of sorption of component $i$ in zone $k, \mathrm{~mol} / \mathrm{kg}-\mathrm{s}$

$r_{p} \quad$ particle radius, $\mathrm{m}$

TCC true counter-current, dimensionless 
time, $s$

$t_{s}$

switching time, s

$u_{k}$

velocity in zone $k, \mathrm{~m} / \mathrm{s}$

$V_{\text {col }}$

volume of SER column, $\mathrm{m}^{3}$

$x$

extent of sorption, dimensionless

z

axial length, m

\section{Greek letters}

$\varepsilon \quad$ bed void fraction, dimensionless

$\mu \quad$ viscosity, $\mathrm{Pa}-\mathrm{s}$

$\rho_{a d s} \quad$ density of sorbent, $\mathrm{kg} / \mathrm{m}^{3}$

$\rho_{\text {cat }} \quad$ density of catalyst, $\mathrm{kg} / \mathrm{m}^{3}$

$v_{i} \quad$ stoichiometric coefficient for component $i$, dimensionless

$\alpha$

flow rate ratio for feed, dimensionless

$\beta \quad$ flow rate ratio for raffinate, dimensionless

$\gamma \quad$ flow rate ratio for extract, dimensionless

$\chi^{2} \quad$ Chi-square 


\section{Appendix A}

\section{Parameters used in the base case simulation}

\begin{tabular}{|c|c|}
\hline$C_{F A}^{f}$ & $1 \mathrm{~mol} / \mathrm{m}^{3}, F A$ feed (Yu et al. $\left.{ }^{32}\right)$ \\
\hline $\mathrm{C}_{\mathrm{CH}_{3} \mathrm{OH}}^{f}$ & $10 \mathrm{~mol} / \mathrm{m}^{3}, \mathrm{CH}_{3} \mathrm{OH}$ feed (Yu et al. $\left.{ }^{32}\right)$ \\
\hline$C_{F A M E}^{f}$ & $0 \mathrm{~mol} / \mathrm{m}^{3}$, FAME feed (Yu et al. $\left.{ }^{32}\right)$ \\
\hline$C_{\mathrm{H}_{2} \mathrm{O}}^{f}$ & $0 \mathrm{~mol} / \mathrm{m}^{3}, H_{2} O$ feed (Yu et al. $\left.{ }^{32}\right)$ \\
\hline$C_{a d s}^{f}$ & $1 \times 10^{-4} \mathrm{~mol} / \mathrm{m}^{3}$, Adsorbent feed (Yu et al. ${ }^{32}$ ) \\
\hline$C_{F A}^{i c}$ & $1 \times 10^{-4} \mathrm{~mol} / \mathrm{m}^{3}, F A$ initial concentration $\left(\mathrm{Yu}\right.$ et al $\left.{ }^{32}\right)$ \\
\hline$C_{M e O H}^{i c}$ & $1 \times 10^{-4} \mathrm{~mol} / \mathrm{m}^{3}, \mathrm{CH}_{3} \mathrm{OH}$ initial concentration (Yu et al. $\left.{ }^{32}\right)$ \\
\hline$C_{F A M E}^{i c}$ & $1 \times 10^{-4} \mathrm{~mol} / \mathrm{m}^{3}, F A M E$ initial concentration $\left(\mathrm{Yu}\right.$ et al. $\left.{ }^{32}\right)$ \\
\hline$C_{\mathrm{H}_{2} \mathrm{O}}^{i c}$ & $1 \times 10^{-4} \mathrm{~mol} / \mathrm{m}^{3}, \mathrm{H}_{2} \mathrm{O}$ initial concentration (Yu et al. ${ }^{32}$ ) \\
\hline$C_{a d s}^{i c}$ & $1 \times 10^{-6} \mathrm{~mol} / \mathrm{m}^{3}$, Adsorbent initial concentration $\left(\mathrm{Yu}\right.$ et al. ${ }^{32}$ ) \\
\hline$D_{L F A}$ & $1.31 \times 10^{-6} \mathrm{~m}^{2} / \mathrm{s}$ (Yu et al. ${ }^{32}$ ) \\
\hline$D_{\mathrm{LCH}_{3} \mathrm{OH}}$ & $3.83 \times 10^{-6} \mathrm{~m}^{2} / \mathrm{s}\left(\right.$ Yu et al. $\left.{ }^{32}\right)$ \\
\hline
\end{tabular}




\begin{tabular}{|c|c|}
\hline$D_{L F A M E}$ & $1.31 \times 10^{-6} \mathrm{~m}^{2} / \mathrm{s}\left(\mathrm{Yu}\right.$ et al.$\left.^{32}\right)$ \\
\hline$D_{\mathrm{LH}_{2} \mathrm{O}}$ & $1.66 \times 10^{-6} \mathrm{~m}^{2} / \mathrm{s}\left(\mathrm{Yu}\right.$ et al..$\left.^{32}\right)$ \\
\hline$d_{t}$ & $0.008 \mathrm{~m}$ (Yori et al. ${ }^{27}$ ) \\
\hline$L$ & $0.1 \mathrm{~m}$ \\
\hline$\rho_{\text {cat }}$ & $139 \mathrm{~kg} / \mathrm{m}^{3}\left(\mathrm{Xiu}^{34}\right)$ \\
\hline$\rho_{\text {ads }}$ & $700 \mathrm{~kg} / \mathrm{m}^{3}$ (Yori et al. ${ }^{27}$ ) \\
\hline$T$ & $333 \mathrm{~K}$ (Yori et al. ${ }^{27}$ ) \\
\hline$u_{I}$ & $5.90 \times 10^{-3} \mathrm{~m} / \mathrm{s}\left(\right.$ Yori et al. $\left.{ }^{27}\right)$ \\
\hline$\mu$ & $4.66 \times 10^{-4} \mathrm{~Pa}$-s (Yori et al..$^{27}$ ) \\
\hline$\varepsilon$ & 0.4 (Yori et al. ${ }^{27}$ ) \\
\hline$H_{F A}$ & 0.36 (Yu et al. ${ }^{35}$ ) \\
\hline $\mathrm{H}_{\mathrm{CH}_{3} \mathrm{OH}}$ & 1 (Yu et al. ${ }^{35}$ ) \\
\hline$H_{F A M E}$ & $0.38\left(\mathrm{Yu}\right.$ et al. $\left.{ }^{35}\right)$ \\
\hline $\mathrm{H}_{\mathrm{H}_{2} \mathrm{O}}$ & $2.78\left(\mathrm{Yu}\right.$ et al. $\left.{ }^{35}\right)$ \\
\hline
\end{tabular}




\section{Literature Cited}

1. Dautzenberg, F. M.; Mukherjee, M., Process intensification using multifunctional reactors. Chemical Engineering Science 2001, 56, (2), 251-267.

2. Narasimharao, K.; Lee, A.; Wilson, K., Catalysts in production of biodiesel: A review. Journal of Biobased Materials and Bioenergy 2007, 1, (1), 19-30.

3. Sun, P. Y.; Zhang, L. X.; Yao, Z. L.; Min, E. Z., Review on the application of novel reactors and process intensification technologies to the production of biodiesel. Shiyou Xuebao, Shiyou Jiagong/Acta Petrolei Sinica (Petroleum Processing Section) 2008, 24, (1), 1-8.

4. Harvey, A. P.; Mackley, M. R.; Seliger, T., Process intensification of biodiesel production using a continuous oscillatory flow reactor. Journal of Chemical Technology and Biotechnology 2003, 78, (2-3), 338-341.

5. Juta Kobayashi, Y. M. S.; umacr; Kobayashi, Multiphase Organic Synthesis in Microchannel Reactors. Chemistry - An Asian Journal 2006, 1, (1-2), 22-35.

6. Wen, Z.; Yu, X.; Tu, S. T.; Yan, J.; Dahlquist, E., Intensification of biodiesel synthesis using zigzag micro-channel reactors. Bioresource Technology 2009, 100, (12), 3054-3060.

7. Hilaly, A., Reactive Chromatography for Biodiesel production. In SRI Report http://crelonweb.eec.wustl.edu/InvitedTalks2006/Hilaly.pdf, 2009.

8. Kiss, A. A.; Dimian, A. C.; Rothenberg, G., Biodiesel production by heatintegrated reactive distillation. Computer Aided Chemical Engineering 2008, 25, 775780. 
9. Kiss, A. A.; Dimian, A. C.; Rothenberg, G., Biodiesel by catalytic reactive distillation powered by metal oxides. Energy and Fuels 2008, 22, (1), 598-604.

10. Cao, P.; Tremblay, A. Y.; DubÃ, M. A., Kinetics of canola oil transesterification in a membrane reactor. Industrial and Engineering Chemistry Research 2009, 48, (5), $2533-2541$.

11. Cao, P.; Dubeİ , M. A.; Tremblay, A. Y., High-purity fatty acid methyl ester production from canola, soybean, palm, and yellow grease lipids by means of a membrane reactor. Biomass and Bioenergy 2008, 32, (11), 1028-1036.

12. Tremblay, A. Y.; Cao, P.; Dube, M. A., Biodiesel production using ultralow catalyst concentrations. Energy and Fuels 2008, 22, (4), 2748-2755.

13. Cao, P.; DubeÌ, M. A.; Tremblay, A. Y., Methanol recycling in the production of biodiesel in a membrane reactor. Fuel 2008, 87, (6), 825-833.

14. Araujo, A. R. T. S.; Saraiva, M. L. M. F. S.; Lima, J. L. F. C.; Korn, M. G. A., Flow methodology for methanol determination in biodiesel exploiting membrane-based extraction. Analytica Chimica Acta 2008, 613, (2), 177-183.

15. Dubeİ , M. A.; Tremblay, A. Y.; Liu, J., Biodiesel production using a membrane reactor. Bioresource Technology 2007, 98, (3), 639-647.

16. A. Kiss, A.; C. Dimian, A.; Rothenberg, G., Biodiesel production by integrated reactive-separation design. In Computer Aided Chemical Engineering, 2007; Vol. 24, pp 1283-1288.

17. C. Dimian, A.; Omota, F.; A. Kiss, A., Process for fatty acid methyl esters by dual reactive distillation. In Computer Aided Chemical Engineering, 2007; Vol. 24, pp 13071312. 
18. Liu, X.; Hu, J.; Du, Z., Study on the preparation of biodiesel fuel from vegetable oil by continuous-flow reactive distillation technique. Petroleum Processing and Petrochemicals 2007, 38, (10), 16-20.

19. Pereira, C. S. M.; Gomes, P. S.; Gandi, G. K.; Silva, V.; Rodrigues, A. E., Multifunctional reactor for the synthesis of dimethylacetal. Industrial \& Engineering Chemistry Research 2008, 47, (10), 3515-3524.

20. Cho, B. K.; Aris, R.; Carr, R. W. In The mathematical theory of a countercurrent catalytic reactor, Proc. Roy. Soc., London, 1982; London, 1982; p 147.

21. Bjorklund, M. C.; Carr, R. W., The simulated countercurrent moving bed chromatographic reactor: a catalytic and separative reactor. Catalysis Today 1995, 25, (2), 159-168.

22. Zhang, Y.; Hidajat, K.; Ray, A. K., Modified reactive SMB for production of high concentrated fructose syrup by isomerization of glucose to fructose. Biochemical Engineering Journal 2007, 35, (3), 341-351.

23. Migliorini, C.; Fillinger, M.; Mazzotti, M.; Morbidelli, M., Analysis of simulated moving-bed reactors. Chemical Engineering Science 1999, 54, (13-14), 2475-2480.

24. Bechtold, M.; Makart, S.; Heinemann, M.; Panke, S., Integrated operation of continuous chromatography and biotransformations for the generic high yield production of fine chemicals. Journal of Biotechnology 2006, 124, (1), 146-162.

25. Ni, J.; Meunier, F. C., Esterification of free fatty acids in sunflower oil over solid acid catalysts using batch and fixed bed-reactors. Applied Catalysis A: General 2007, $333,(1), 122-130$. 
26. Kreyszig, E., ADVANCED ENGINEERING MATHEMATICS. 8 ed.; John Wiley \& Sons, Inc.: New York, 1999.

27. Yori, J. C.; D'Ippolito, S. A.; Pieck, C. L.; Vera, C. R., Deglycerolization of biodiesel streams by adsorption over silica beds. Energy \& Fuels 2007, 21, (1), 347-353.

28. Yu, W. F.; Hidajat, K.; Ray, A. K., Modeling, simulation, and experimental study of a simulated moving bed reactor for the synthesis of methyl acetate ester. Industrial \& Engineering Chemistry Research 2003, 42, (26), 6743-6754.

29. Danckwerts, P. V., Continuous flow systems : Distribution of residence times. Chemical Engineering Science 1953, 2, (1), 1-13.

30. Lode, F.; Houmard, M.; Migliorini, C.; Mazzotti, M.; Morbidelli, M., Continuous reactive chromatography. Chemical Engineering Science 2001, 56, (2), 269-291.

31. Fricke, J.; Schmidt-Traub, H., A new method supporting the design of simulated moving bed chromatographic reactors. Chemical Engineering and Processing 2003, 42, (3), 237-248.

32. Yu, W. F.; Hidajat, K.; Ray, A. K., Determination of adsorption and kinetic parameters for methyl acetate esterification and hydrolysis reaction catalyzed by Amberlyst 15. Applied Catalysis a-General 2004, 260, (2), 191-205.

33. Ding, Y.; Alpay, E., Adsorption-enhanced steam-methane reforming. Chemical Engineering Science 2000, 55, (18), 3929-3940.

34. Xiu, G.; Soares, J. L.; Li, P.; Rodrigues, A. E., Simulation of five step one bed sorption enhanced reaction process. AIChE Journal 2002, 48, 2817. 
35. Yu, W. F.; Hidajat, K.; Ray, A. K., Application of multiobjective optimization in the design and operation of reactive SMB and its experimental verification. Industrial \& Engineering Chemistry Research 2003, 42, (26), 6823-6831.

36. Meissner, J. P.; Carta, G., Continuous Regioselective Enzymatic Esterification in a Simulated Moving Bed Reactor. Industrial \& Engineering Chemistry Research 2002, 41, (19), 4722-4732.

37. Gan, M.; Pan, D.; Ma, L.; Yue, E.; Hong, J., The Kinetics of the Esterification of Free Fatty Acids in Waste Cooking Oil Using Fe2(SO4)3/C Catalyst. Chinese Journal of Chemical Engineering 2009, 17, (1), 83-87. 


\section{List of figures}

Figure 1: Prediction of conversion of $F A$ by reaction into FAME

Figure 2: Schematic of SMBR for FAME Production (Q indicates flowrates in different zones)

Figure 3: Operating parameters for FAME synthesis by SMBR as represented on the flow ratio $m_{I}-m_{I V}$ parameter plane for a given residence time. * represents the operating points.

Figure 4: Outlet concentration from fixed bed chromatographic reactor producing FAME from FA esterification, $u=0.0002 \mathrm{~m} / \mathrm{s}, L=0.1 \mathrm{~m}$ and $\mathrm{CH}_{3} \mathrm{OH} / F A=5$

Figure 5: Outlet concentration from a fixed bed chromatographic reactor for different lengths of the bed $\left(u=2 \times 10^{-4} \mathrm{~m} / \mathrm{s}, \mathrm{CH}_{3} \mathrm{OH} / F A=15.0\right)$

Figure 6: Outlet concentration from a fixed bed chromatographic reactor for different superficial velocities $\left(L=0.5 \mathrm{~m}, \mathrm{CH}_{3} \mathrm{OH} / \mathrm{FA}=15.0\right)$

Figure 7: Outlet concentration from a fixed bed chromatographic reactor for different $\mathrm{CH}_{3} \mathrm{OH} / \mathrm{FA}$ ratio $\left(L=0.5 \mathrm{~m}, u_{I}=1 \times 10^{-4} \mathrm{~m} / \mathrm{s}\right)$

Figure 8: Concentration profile along the length of the SMBR after four feed port switches $\left(t_{s}=600 \mathrm{~s}, L=0.25 \mathrm{~m}, u_{I}=2.4 \times 10^{-4} \mathrm{~m} / \mathrm{s}\right)$

Figure 9: Raffinate Mole Fraction for four feed port switches at $t=2400 \mathrm{~s}\left(t_{s}=600 \mathrm{~s}\right.$, $L=0.25 \mathrm{~m}, u_{I}=2.4 \times 10^{-4} \mathrm{~m} / \mathrm{s}$ )

\section{$\underline{\text { List of Tables }}$}

Table 1: Kinetic rate constants in LHHW mechanism for esterification of $F A$ to FAME

Table 2: Effect of parameters on the performance of SMBR

Table 4: Summary of the effect of design and operating parameters on the performance of SER and SMBR 


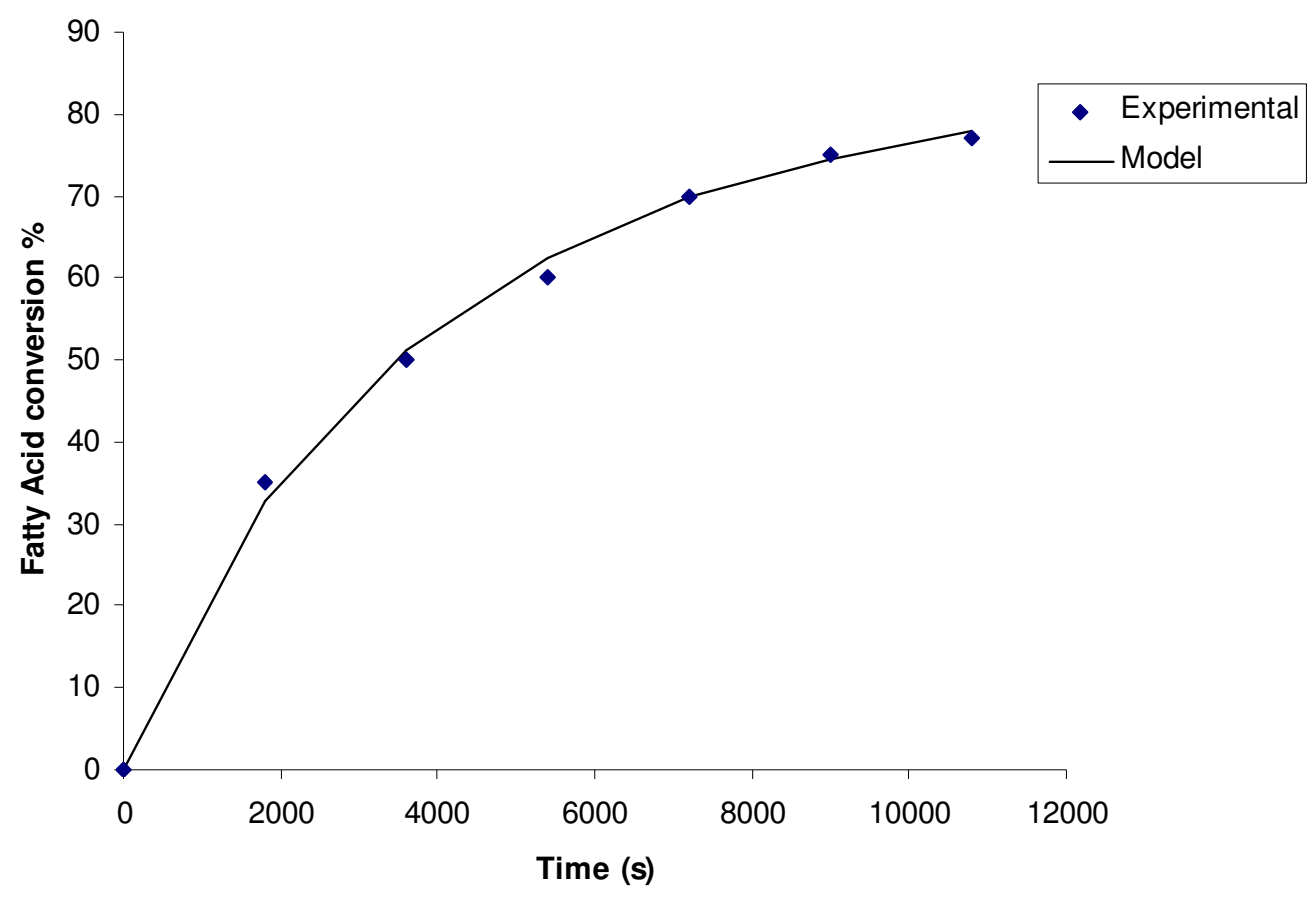

Figure 10: Prediction of conversion of $F A$ by reaction into FAME 


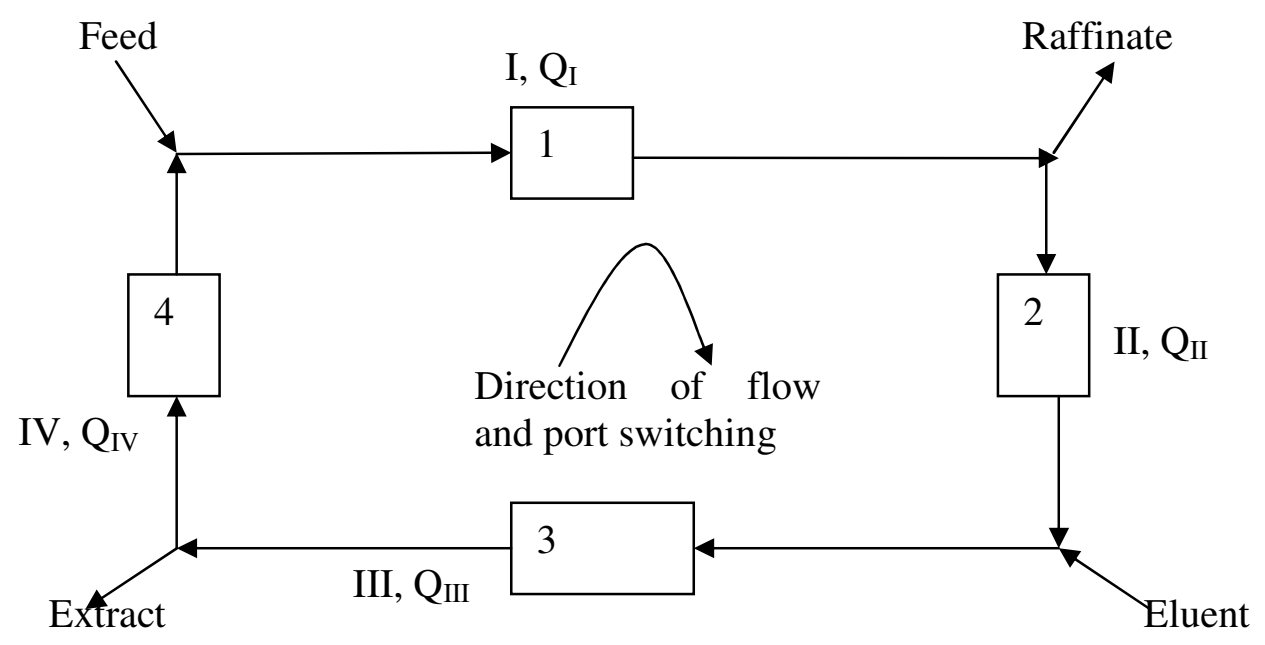

Figure 11: Schematic of SMBR for FAME Production (Q indicates flowrates in different zones) 


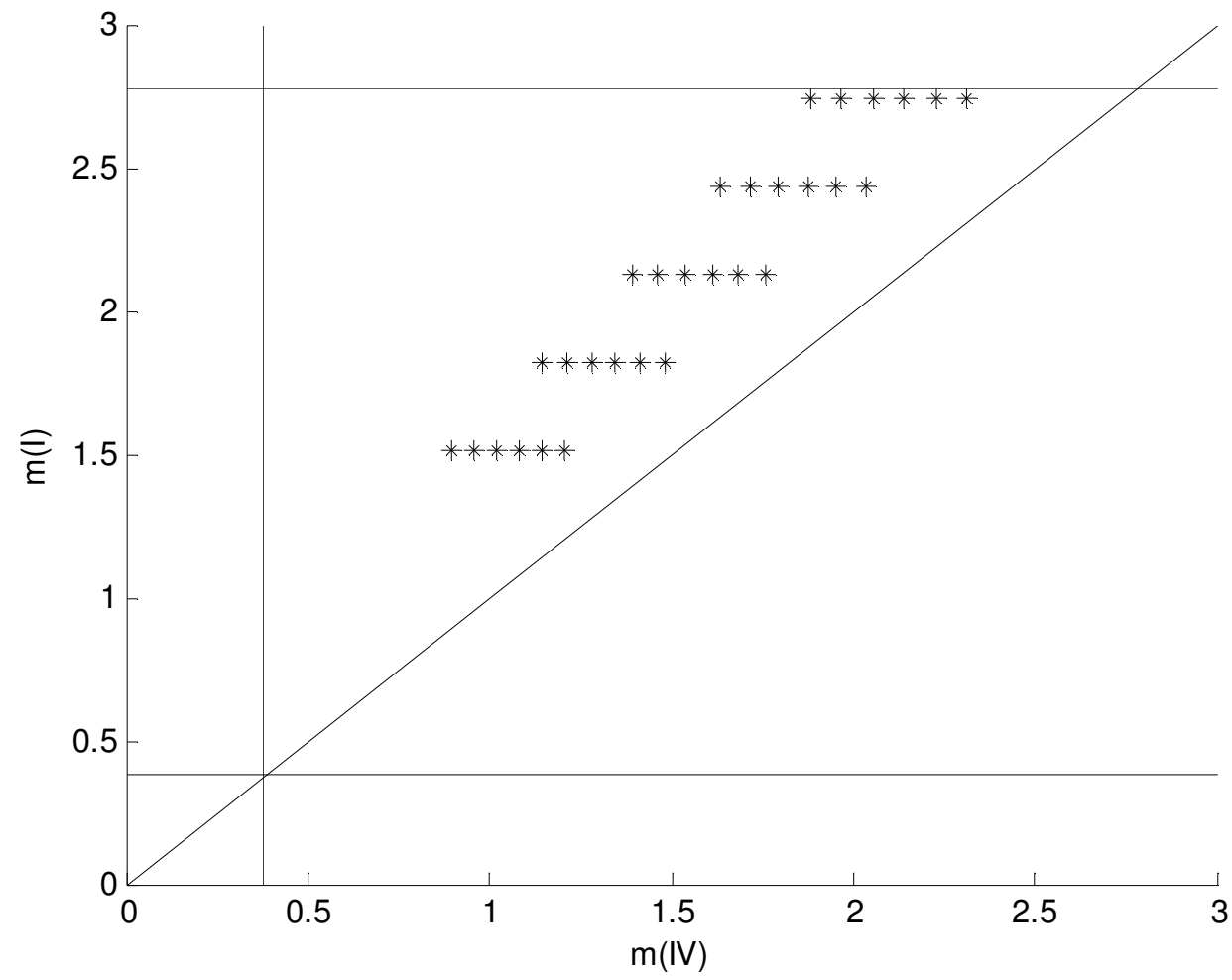

Figure 12: Operating parameters for FAME synthesis by SMBR as represented on the flow ratio $m_{I}-m_{I V}$ parameter plane for a given residence time. $*$ represents the operating points. 


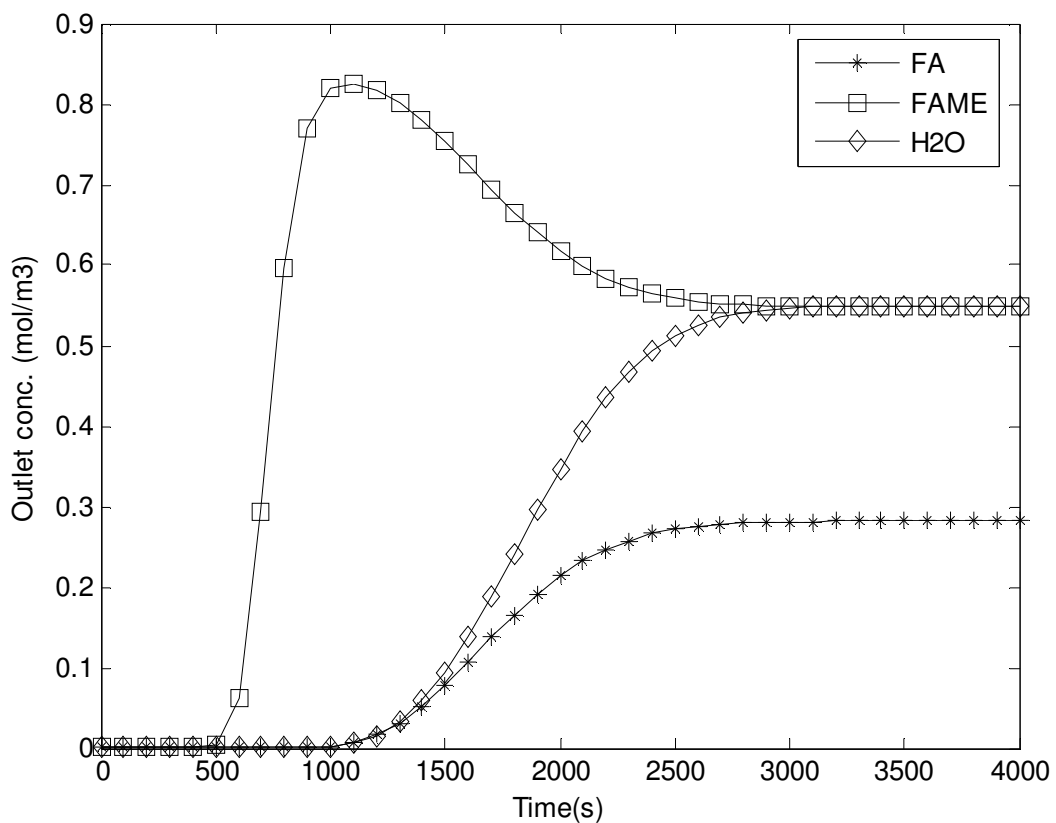

Figure 13: Outlet concentration from fixed bed chromatographic reactor producing FAME from FA esterification, $u=2 \times 10^{-4} \mathrm{~m} / \mathrm{s}, \mathrm{L}=0.1 \mathrm{~m}$ and $\mathrm{CH}_{3} \mathrm{OH} / F A=5$ 


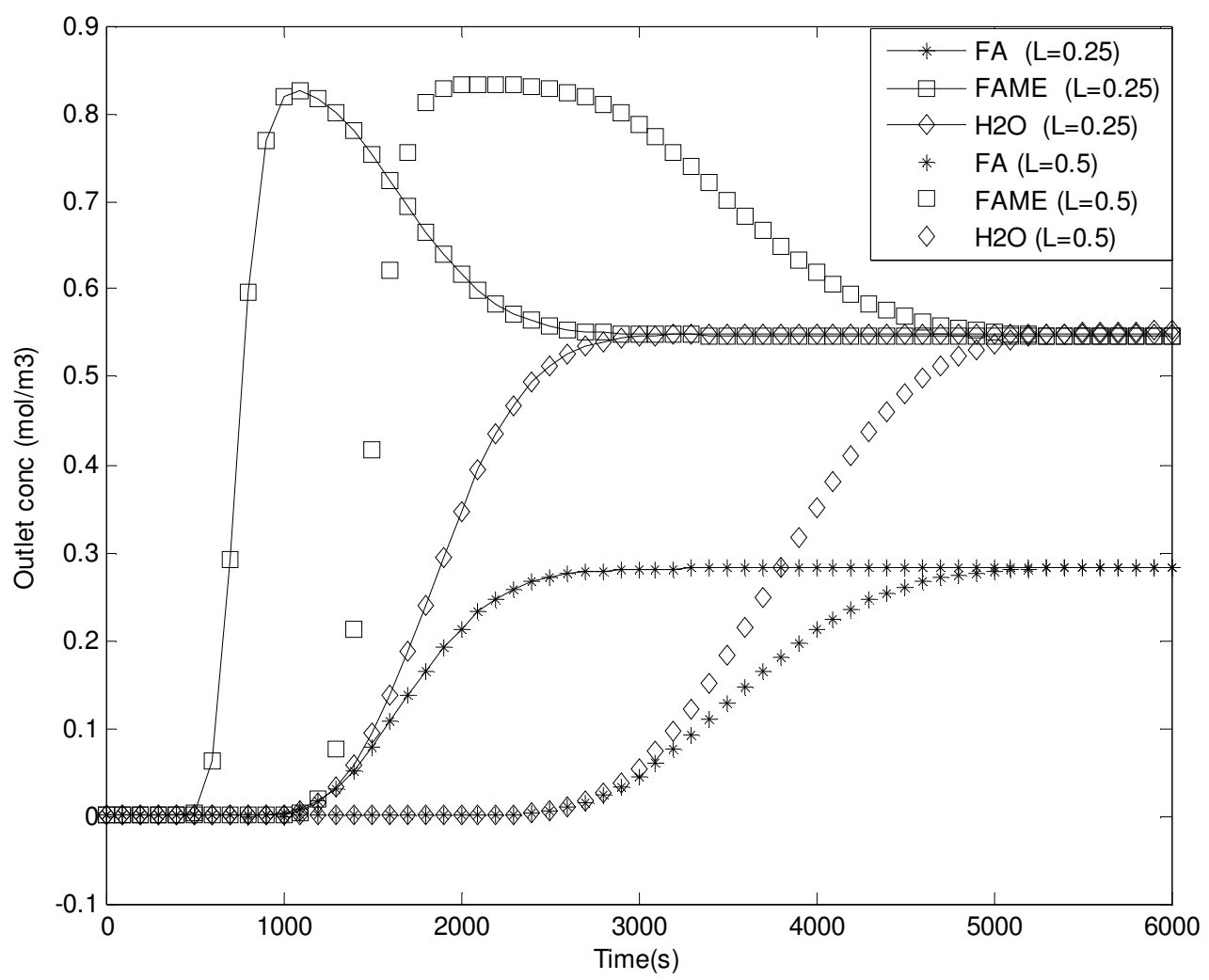

Figure 14: Outlet concentration from a fixed bed chromatographic reactor for different lengths of the bed $\left(u=2 \times 10^{-4} \mathrm{~m} / \mathrm{s}, \mathrm{CH}_{3} \mathrm{OH} / F A=15.0\right)$ 


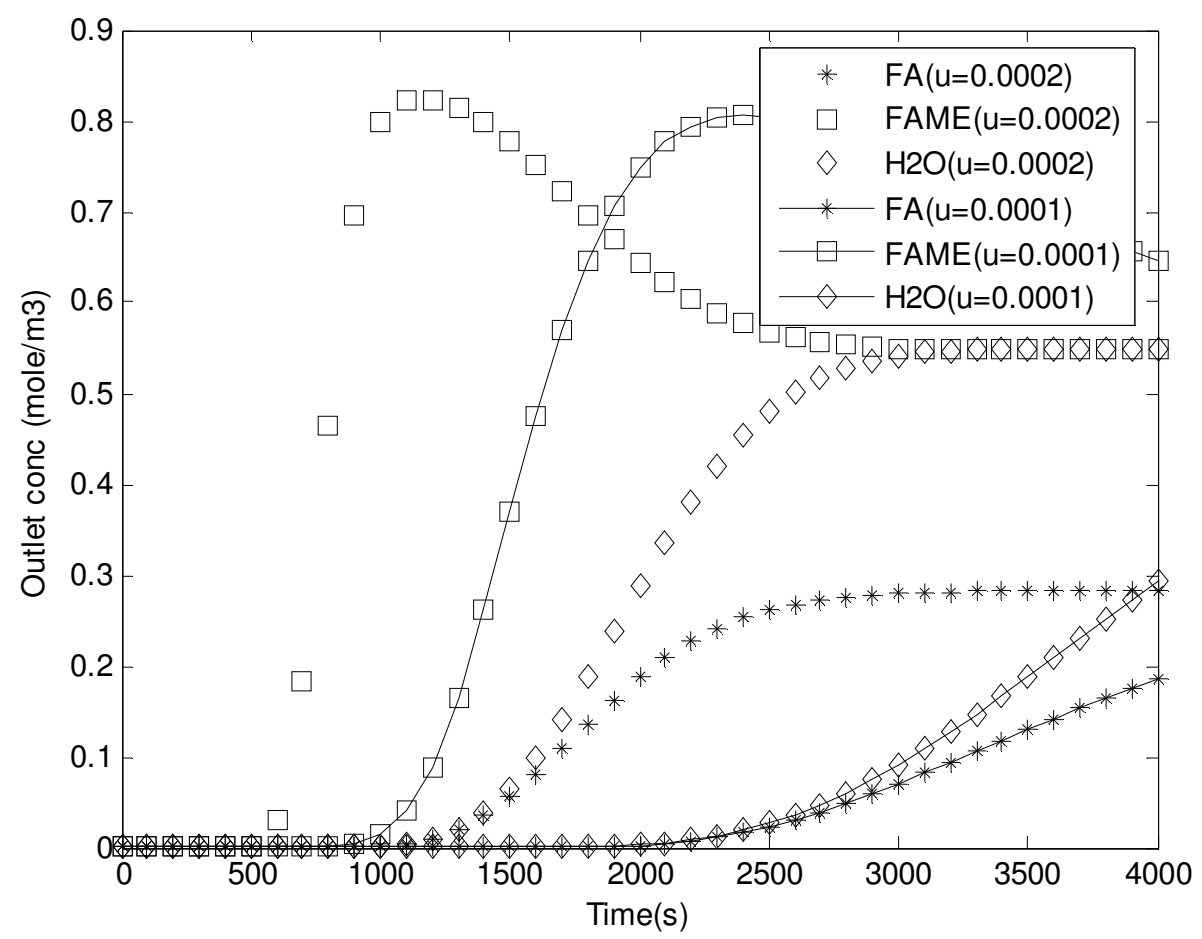

Figure 15: Outlet concentration from a fixed bed chromatographic reactor for different superficial velocities $\left(L=0.5 \mathrm{~m}, \mathrm{CH}_{3} \mathrm{OH} / \mathrm{FA}=15.0\right)$ 


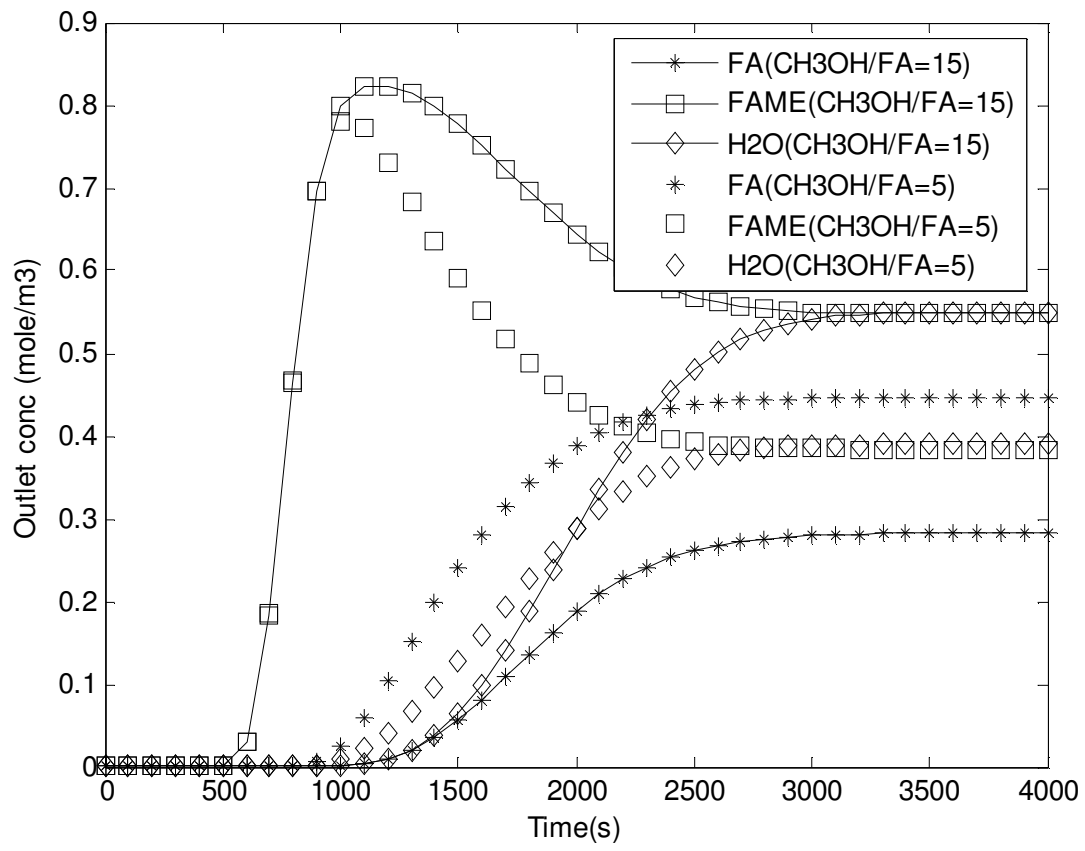

Figure 16: Outlet concentration from a fixed bed chromatographic reactor for different $\mathrm{CH}_{3} \mathrm{OH} / \mathrm{FA}$ ratio $\left(L=0.5 \mathrm{~m}, u=1 \times 10^{-4} \mathrm{~m} / \mathrm{s}\right)$ 

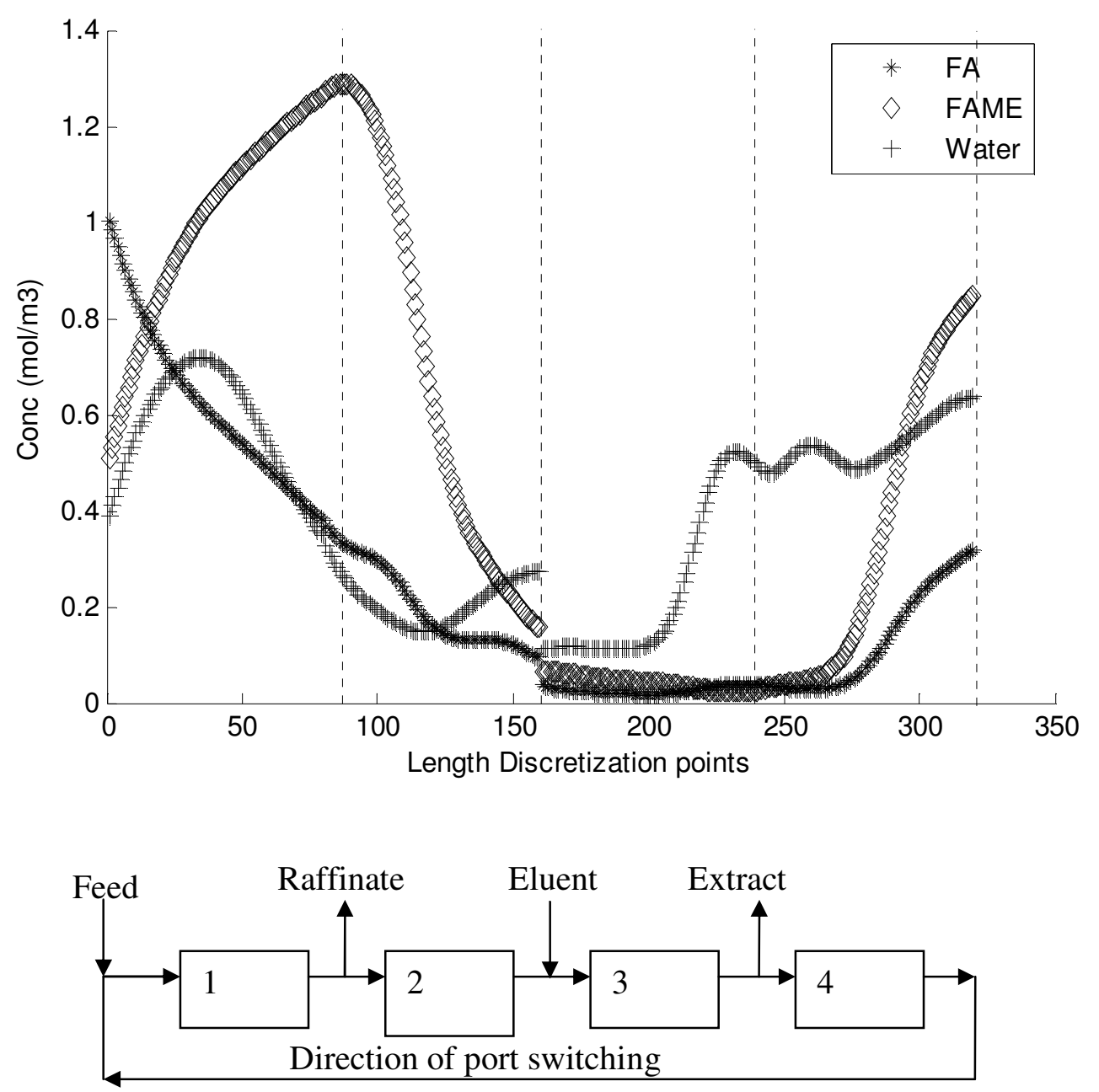

Figure 17: Concentration profile along the length of the SMBR after four feed port switches at $t=2400 \mathrm{~s}\left(t_{s}=600 \mathrm{~s}, L=0.25 \mathrm{~m}, u=2.4 \times 10^{-4} \mathrm{~m} / \mathrm{s}\right)$ 


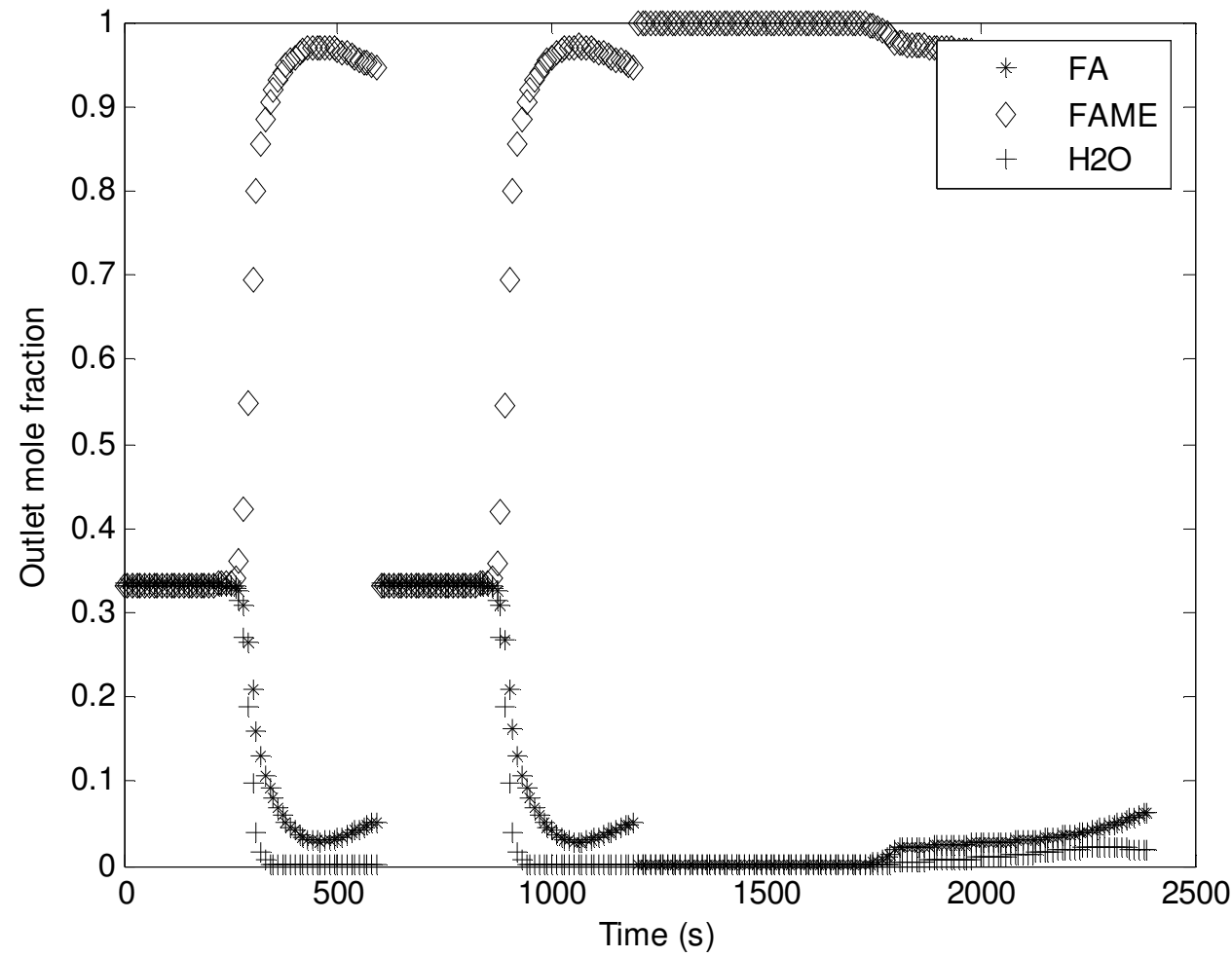

Figure 18: Raffinate Mole Fraction for four feed port switches $\left(t_{s}=600 \mathrm{~s}, L=0.25 \mathrm{~m}\right.$, $u=2.4 \times 10^{-4} \mathrm{~m} / \mathrm{s}$ ) 
Table 5: Kinetic rate constants in LHHW mechanism for esterification of FA to FAME

\begin{tabular}{|l|l|l|l|l|l|l|l|l|}
\hline Kinetic & $K_{1}$ & $K_{2}$ & $K_{3}$ & $K_{4}$ & $K_{5}$ & $k_{f}(\mathrm{~mol}$ & $R S S Q$ & $\chi^{2}$ \\
parameter & & & & & & & & \\
\hline Value & 17.31 & 6.72 & 2.06 & 54.28 & 16.75 & 0.65 & 0.001 & 0.003 \\
\hline
\end{tabular}


Table 6: Effect of parameters on the performance of SMBR

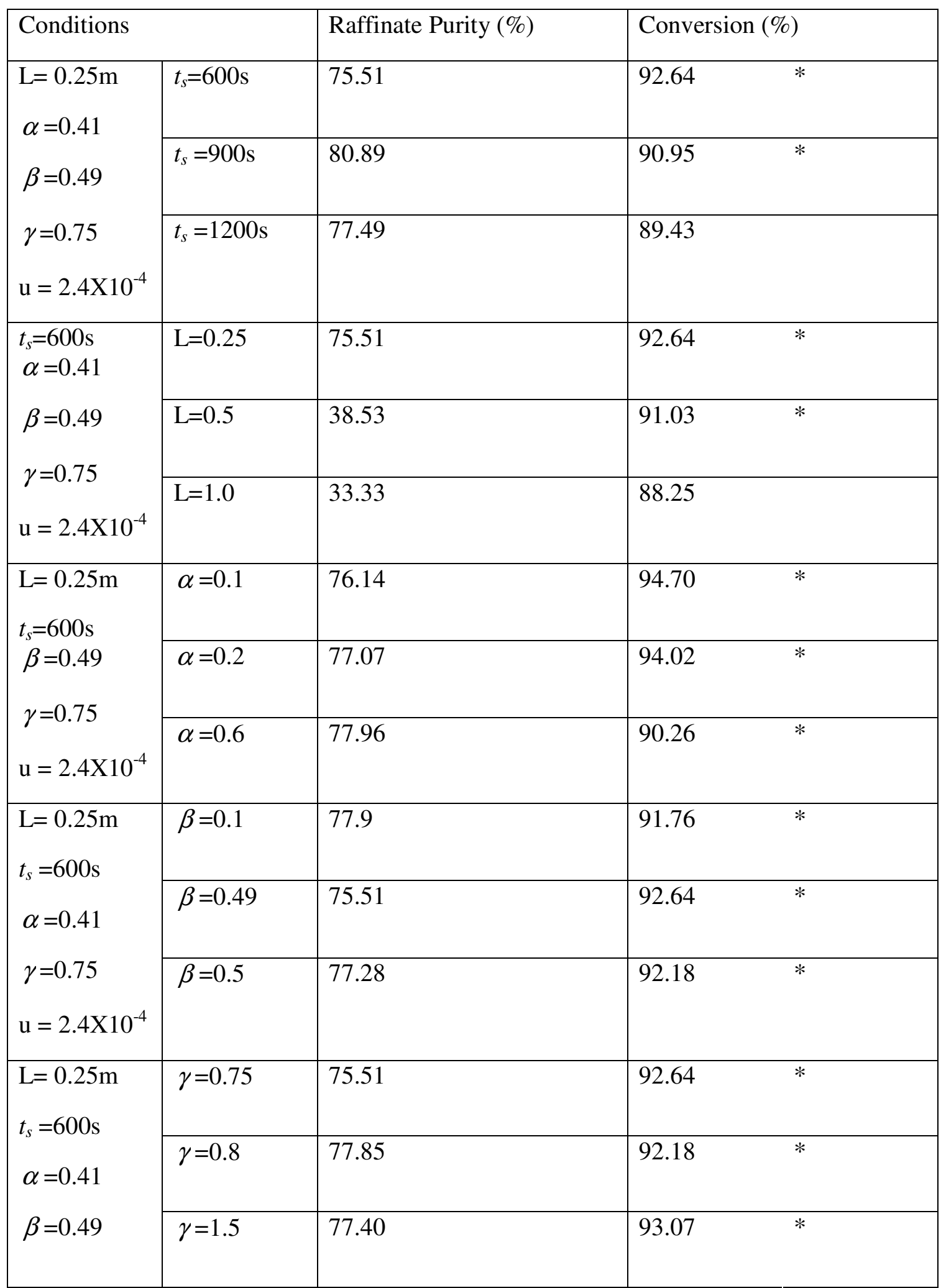


$\mathrm{u}=2.4 \mathrm{X} 10^{-4}$ 
Table 7: Summary of the effect of design and operating parameters on the performance of SER and SMBR

\begin{tabular}{|c|c|c|}
\hline Parameter & Effects & \\
\hline & SER & SMBR \\
\hline Superficial velocity & $\begin{array}{l}\text { High purity FAME produced for } \\
\text { a longer duration of time with } \\
\text { decrease in superficial velocity }\end{array}$ & \\
\hline $\begin{array}{l}\text { Length of the } \\
\text { reactor-adsorber } \\
\text { unit }\end{array}$ & $\begin{array}{l}\text { High purity FAME for a longer } \\
\text { duration of time due to higher } \\
\text { residence time }\end{array}$ & $\begin{array}{l}\text { Monotonic decrease in } \\
\text { conversion and substantial } \\
\text { decrease in raffinate purity }\end{array}$ \\
\hline Feed ratio & $\begin{array}{l}\text { Shifts the equilibrium } \\
\text { concentration }\end{array}$ & \\
\hline Switching time & & $\begin{array}{l}\text { Monotonic decrease in } \\
\text { conversion and a maximum in } \\
\text { purity }\end{array}$ \\
\hline $\begin{array}{l}\text { Flow rate in reload } \\
\text { zone } \boldsymbol{\alpha}\end{array}$ & & $\begin{array}{l}\text { Decrease in conversion and an } \\
\text { increase in purity }\end{array}$ \\
\hline $\begin{array}{l}\text { Flow rate of } \\
\text { raffinate } \boldsymbol{\beta}\end{array}$ & & $\begin{array}{l}\text { A minimum in purity and a } \\
\text { maximum in conversion }\end{array}$ \\
\hline Flow rate of eluent $\gamma$ & & $\begin{array}{l}\text { A maximum in purity and a } \\
\text { minimum in conversion }\end{array}$ \\
\hline
\end{tabular}

